\title{
VULNERABILITY OF THE EUROPEAN AIR TRANSPORT NETWORK TO MAJOR AIRPORT CLOSURES FROM THE PERSPECTIVE OF PASSENGER DELAYS: RANKING THE MOST CRITICAL AIRPORTS
}

\author{
Augusto Voltes-Dorta (corresponding author) \\ University of Edinburgh Business School \\ Management Science and Business Economics Group \\ EH8 9JS Edinburgh, United Kingdom \\ avoltes@becarios.ulpgc.es \\ Héctor Rodríguez-Déniz \\ Universidad de Las Palmas de Gran Canaria \\ Facultad de Economia y Turismo D.3.01 \\ 35017 Las Palmas de Gran Canaria, Spain \\ hrodriguez@,becarios.ulpgc.es \\ Pere Suau-Sanchez \\ Cranfield University \\ Centre for Air Transport Management \\ MK43 0TR, Bedfordshire, United Kingdom \\ p.suausanchez@cranfield.ac.uk
}

\begin{abstract}
This paper analyzes the vulnerability of the European air transport network to major airport closures from the perspective of the delays imposed to disrupted airline passengers. Using an MIDT dataset on passenger itineraries flown during February 2013, full-day individual closures of the 25 busiest European airports are simulated and disrupted passengers then relocated to minimum-delay itineraries. Aggregate delays are used to rank the criticality of each airport to the network, with the possibility of disaggregating the impact across geographical markets. The results provide useful reference values for the development of policies aimed at improving the resilience of air transport networks.
\end{abstract}

Keywords: Air transport networks, resilience, criticality, passenger recovery.

\section{INTRODUCTION}

Air transport networks are vulnerable to external events, even those that only have a local impact. For example, a single airport closure due to poor weather conditions or an industrial action may affect the network's overall performance. The final impact can range from a few delays and missed connections to significant economic losses (Mazzocchi et al., 2010). One of the possible reasons behind this vulnerability is that ensuring resilient operations has been secondary to profit maximization and other geopolitical factors in airline network development during the last decades (Lordan et al., 2014b). On top of that, predicted rates of growth in air transport demand (ICAO, 2013) in combination with large shocks such as 9/11, or the 2010 Volcanic Ash Cloud, can reduce the ability to cope with such disturbances and put additional pressures on air transport networks (Cardillo et al., 2013). Within this context, reducing the vulnerability and improving the resilience of transport networks has been recognized by the European Commission as a high level goal for 2050 (EC, 2014a).

There is a decent body of literature on the resilience of air transport that largely employs complex network theory to analyse the topological properties of airline networks and their implications in terms of vulnerability to airport failures or the closure of air corridors. There is a disconnection, however, between these analyses and the actual impact of air transport disruptions on the final users (i.e. the passengers that experience travel delays). Indeed, only few of these studies consider the important aspect of how airlines relocate disrupted passengers and, to the best of our knowledge, no previous paper uses actual passenger demand data to that end. This situation contrasts with a richer literature in other modes, such 
as rail or road, where the analysis of resilience and vulnerability is more developed, and the implications in terms of direct cost to the user (e.g. travel delays) in the event of a disruption in service have been modelled in more detail (e.g. Jenelius et al., 2006).

Thus, this paper builds upon the concepts developed in previous studies with the objective to develop a new method to incorporate demand data into the assessment of vulnerability of the European air transport network to major airport closures. Using a Market Information Data Transfer dataset (commonly known as MIDT) on passenger itineraries during February 2013, full-day individual closures of the 25 busiest European airports are simulated and disrupted passengers are relocated to the delay-minimizing itineraries where seat capacity is available. A multi-layered network is constructed, where airlines are only able to relocate passengers within their own alliances' flight networks. Vulnerability is measured by the aggregate delays imposed to the disrupted passengers as well as the amount of unsatisfied demand in each closure scenario. This allows us to rank the most critical airports in the European network. In addition, we can disaggregate the impact on geographical markets (with special focus on passengers travelling in routes within the European Economic Area, from now on "intraEEA" routes). Information on how the traffic is redistributed under each scenario is provided as well, leading to an exploratory discussion on the main drivers of airport criticality. The results aim to complement the stream of literature that employs complex network theory to the same end and also provide useful reference values for the development of policies aimed to reduce the vulnerability and improve the resilience of air transport networks.

The rest of this paper is structured as follows: Section 2 provides a literature review on the analysis of resilience and vulnerability of air transport networks and discusses our contribution. Section 3 describes the supply and demand datasets. Then, the methodological process is explained, with particular focus on the passenger relocation algorithm. Section 4 presents the results and discusses their main implications. Finally, Section 5 summarizes our findings, addresses the limitations of our model, and proposes new paths for future research.

\section{LITERATURE REVIEW AND CONTRIBUTION}

\subsection{Basic definitions}

Vulnerability is a concept that is complementary to the ideas of resilience ${ }^{1}$, robustness, or reliability. Vulnerability was defined by Berdica (2002) as the "susceptibility of a system to experience disruptions that can affect its functionality". In the context of a transportation network, functionality can be understood as operability or serviceability, i.e. the possibility of using any node of link of the network during a given period. As noted by Jenelius et al., (2006), this definition of vulnerability can be linked to the general concept of risk and thus disaggregated in two components: 1) the probability of the disruptive event occurring, and 2) the consequences of the disruptive event (system damage). Given the difficulties in estimating the probabilities of extreme events, such as natural disasters or terrorist attacks, authors like Berdica (2002) or D'Este and Taylor (2003) argue that measuring the magnitude of consequences should be the primary focus of vulnerability studies. This leads to the concept of "conditional vulnerability", defined as the measurement of system damage given that the disruptive event occurs.

It is also possible to measure the criticality of a certain component of the system, such as any particular nodes or links. A critical component has a high probability of failure and creates a large amount of damage if removed. In parallel to above, ignoring the probability of failure in

\footnotetext{
${ }^{1}$ Rose (2007) defined resilience as the ability of a system to maintain functionality when disrupted, with particular focus on the speed at which the system returns to normal
} 
the analysis gives rise to the concept of "conditional criticality" defined by Jenelius et al., (2006), as the measurement of the damage caused by the failure of the relevant component.

\subsection{Previous studies}

The resilience and vulnerability of network systems has been an area of great interest because strategic economic sectors such as energy, utilities, transport, or telecommunications are dependent on networks to function. In regards to transport networks, Faturechi and MillerHooks, (2015) list approximately 200 published works on a wide range of modes, including metro/subway systems (e.g. Derrible and Kennedy, 2010; Li and Kim, 2014; D'Lima and Medda, 2015); maritime transport (e.g. Berle et al., 2011; Thekdi and Santos, 2015: port operations; Ducruet et al., 2010: liner shipping; DiPietro et al., 2014: inland waterways); rail (e.g. De los Santos et al., 2012; Cacchiani et al., 2014; Rodríguez-Núñez and GarcíaPalomares, 2014); road (e.g. Chen et al., 2002; Jenelius et al., 2006; Jenelius and Mattsson, 2012; El-Rashidy and Grant-Muller, 2014; Cats and Jenelius, 2015); air transport (covered below); and finally, there have also been attempts at developing models for intermodal resilient operations (e.g. Chen and Miller-Hooks, 2012).

After a comprehensive review of studies, Mattsson and Jenelius (2015) described two main approaches to measure vulnerability of transport networks: a) topological vulnerability, and b) system-based vulnerability.

In the topological vulnerability approach, the network is represented as an abstract graph and the researcher measures system damage as a result of changes in network topology after a disruption affects one or more nodes or links. This type of approach typically uses only supply data on available infrastructure and service frequencies. The topological properties of networks are characterised by indicators such as average shortest path or degree distribution, which determine how the network will be classified within a number of generic structures. The study of Zhang et al. (2015) analyses of 17 different network structures, concluding that factors such as a higher average degree (i.e. more well-connected nodes), structural redundancies ${ }^{2}$, and excess capacity reduce the vulnerability of transport networks.

In the system-based vulnerability approach, the network graph is complemented with information on actual or predicted traffic flows, and the interaction between supply and demand under disruptions is modelled, for example, with a user re-routing algorithm. Examples of this system-based approach can be found in Jenelius et al. (2006), De los Santos et al. (2012), or Rodríguez-Núñez and García-Palomares (2014), where road and rail network vulnerability under a variety of disrupting scenarios is measured according to the total delays experienced by the users, who need to alter their original itineraries, as well as the amount of unsatisfied demand. This second approach is the one we prefer. The reason is that it allows us to obtain a more detailed measurement of "conditional vulnerability" and "conditional criticality", as defined in the previous subsection, since the consequences for the users (in terms of travel costs) are now directly quantified.

Most of the studies on vulnerability and resilience of air transport networks employ a supplybased topological approach (e.g., Zanin and Lillo, 2013; Lordan et al., 2014a). By using a network characterisation of airports as nodes and air corridors as links (either weighted or unweighted by capacity), airline networks can be classified according to their topological properties. In an air transport context, hub-and-spoke networks are generally considered to have "scale-free" properties (i.e. concentrated around large nodes) while point-to-point

\footnotetext{
2 The concept of structural redundancy is linked to the network's cyclicity. For example, a circular subway network can maintain functionality even if one station closes (Derrible and Kennedy, 2010).
} 
networks lean more towards to the "small-world" class ${ }^{3}$ (Zanin and Lillo, 2013). Studies such as Guimerà et al. (2005), Guida and Maria (2007), Reggiani et al. (2010), Wang et al. (2011) and Zeng et al. (2011) apply these methods to identify the respective network's most relevant airports, which are generally those with highest degree centrality (i.e., largest number of destinations), closeness (i.e. shortest average distance to all other airports) or betweenness centrality (i.e., lying in the largest number of shortest-paths between other airport pairs).

By analysing the evolution of these indicators in the Brazilian network over 12 years, Rocha (2009) found that large airports gain importance over time as airlines move capacity to the most profitable routes. However, as network concentration around pivotal nodes increases so does the network's vulnerability, mainly as a result of the lack of structural redundancies that support recovery of traffic flows via alternative routings (Zhang et al., 2015). Hence, while "scale-free" networks are considered to be more resilient to random failures, this comes at the cost of higher vulnerability to targeted attacks to their most central nodes (Albert et al., 2000). In this regard, the recent years have seen a growing interest in measuring the damage caused by the removal of nodes (i.e. airport closures) and/or links (i.e. air corridors) in order to determine the network's vulnerability to these events.

The purely topological approach to assess this damage in air transport networks does not explicitly take into account the need to redistribute the disrupted traffic. The study by Chi and Cai (2004) for the US airport network analyses how the main topological indicators change after nodes or links are removed. They found that removing the top $10 \%$ most connected airports would reduce network efficiency by $25 \%$. Lordan et al. (2014a) modeled the global airport network with unweighted links and developed a measure of the damage produced by both random failures and targeted attacks based on the number of disconnected airports that result from them. Betweenness centrality is used as one of the selection criteria for targeted attacks. Results are similar to those obtained by Guimerà et al. (2005) in which the most critical airports turn out to be the largest and best connected (e.g. Frankfurt, Paris, or Amsterdam) as well as the main gateways to isolated areas (e.g. Anchorage, Tahiti). Janic (2015) relied on disconnected flights as a measure of network damage, also leading to the aforementioned conclusion that larger airports (i.e. Atlanta in the case of 2012 Hurricane Sandy) tend to be the most critical. More recently, Lordan et al. (2015) analysed the resilience of the global airline alliance networks using similar topological indicators, concluding that Star Alliance is the most resilient, followed by SkyTeam and Oneworld. One of the main reasons is that the Star Alliance network has a more continuous distribution of degree and betweenness centrality among its constituent airports, while the other alliances are dominated by few large hubs. In that regard, the degree of vulnerability of the dominating alliance is expected to be one of the main predictors of airport criticality.

A system-based approach to assess network resilience incorporates information on passenger flows in order to model the disruption costs from the user's perspective. To that end, any relevant model would need to replicate the challenges arising from irregular airline operations, with particular focus on the recovery of aircraft, crews, and passengers in an optimal (i.e. cost-minimizing) fashion. As noted by Barnhart (2009), there are a number of strategies that airlines can use to adjust schedule operations, including delaying and cancelling flights, reassigning aircraft or crews to different routes, and relocating disrupted passengers. All these adjustments are subject to a number of restrictions, including crew work rules, maintenance schedules, and aircraft and passenger positioning. There is a large body of literature devoted to providing efficient methods to solve these optimization problems under different scenarios (e.g., Yan and Lin, 1997; Lettovsky et al., 2000; Abdelghany et al. 2008;

\footnotetext{
${ }^{3}$ Real-life air transport networks, however, can also present mixed characteristics (Guimerà et al., 2005).
} 
Bratu and Barnhart, 2006; Petersen et al., 2012, and Maher, 2015) as well as measuring the costs of these disruptions for airlines and passengers (e.g., Schavell, 2000; Allan et al., 2001; Schaefer and Millner, 2001; Janic, 2005; Khol et al., 2007; Janic, 2015). From the passenger perspective, there are different cost measures, including the number of passengers affected (missed connections and cancellations), the proportion of those relocated, and the total delay experienced, measured by the difference between the original and rescheduled itineraries (Bratu and Barnhart, 2006). These measures of user costs are, in essence, the same ones defined by Jenelius et al., (2006) to represent system damage in their road network study.

In the intersection between the topological and the system-based approach, there is a relatively recent stream of literature that focuses on measuring the changes in network topology as a result of passenger rescheduling. However, none of the published studies so far use detailed demand data and, instead, passenger flows are either inferred from the existing capacity, or they are only available at a flight sector level (without knowing the passengers' full itineraries). For simplicity, these studies retain a view of air transport networks as isolated components of overall transport networks. The goal is to determine how vulnerable the provision of air transport is in a particular country or region without considering the possibility of switching to other transport modes in case of an external shock. Cardillo et al. (2013), working with the European network, developed a passenger rescheduling algorithm and determined the change in the network's topological indicators after simulating random failures and assigning the disrupted passengers to alternative itineraries. They define a multilayered network, with each layer representing an individual airline's flight network. In order to make the rescheduling more realistic, passenger recovery options within the same layer are given priority. Results show that the definition of a multi-layered structure negatively affects the measures of network resilience as it effectively restricts the options for passenger relocation. Also relevant is the contribution by Hossain et al. (2013) for Australian airports, where variables such as airport capacity and ground transfers between airports were included in the rescheduling algorithm. They estimated the unit cost of relocation associated to each airport closure as a measure of airport criticality and then ranked the airports according to that dimension. They found a high correlation $(78 \%+)$ between the relocation costs and the indicators of degree and betweenness centrality. In spite of that, the impact of a closure can be mitigated by having close surrogate airports to serve the stranded passengers.

\subsection{A new method using demand data}

Our paper builds on the last two contributions (i.e., Cardillo et al., (2013) and Hossain et al. (2013)) in which a system-based approach to measure network vulnerability is undertaken, though with a much stronger methodological focus on passenger relocation than on the analysis of network topology. In addition, we adapt Jenelius et al. (2006) concepts to an air transport context by measuring system vulnerability and node criticality according to passenger delays and unsatisfied demand conditional to different disruption scenarios. Furthermore, we maintain the simplifying view of air transport networks as an isolated component, meaning that the passengers in our model will not fully substitute air travel by road or rail. Nevertheless, we do consider ground transport for broadening the set of alternatives available to disrupted passengers and aspects like intermodal integration can help to explain how vulnerable airline operations are at a particular airport.

The present study adds to the literature in four key areas. The first and most important is the development of an enhanced relocation algorithm where disrupted passengers are offered options that cover their entire journey. This is only possible because we use demand data to characterise traffic flows within the European Air Transport Network. In addition, it is possible, for the first time, to disaggregate the network impact according to different 
origin/destination markets, with particular focus on the intra-European market which is of great interest for EU policy-makers. The second novelty is the use of a multi-layered network defined at an alliance/partnership level (as recommended by Cardillo et al., 2013; and Zanin, 2015). The reason is that a significant proportion of bookings in our dataset are operated by two or more airline partners and, hence, the individual airlines' flight networks may not be able to provide relocation alternatives. Thirdly, we provide the first ranking of airport criticality within the European network based on non-topological measures of network damage. Finally, we also aim to explore the main drivers of airport criticality under our new approach and discuss how the main conclusions from the existing body of research on topological vulnerability of air transport networks relate to our results.

\section{DATA AND METHODOLOGY}

\subsection{Scope of analysis and methodological stages}

In this paper, "European airports" are defined as those located in any country that is totally or partially in Europe. European airports can be split between European Economic Area (EEA) and non-EEA members. Switzerland is included in the EEA group. The European air transport network is characterised by all worldwide air passengers that travel through at least one European airport during a certain period. These concepts, along with the datasets described below, delimit the geographical and temporal dimensions of this study.

In regards to methodology, the whole process can be split in three stages. First, we generate a baseline scenario by assigning a flight combination with a minimum travel time for each observed passenger itinerary. Second, we simulate the closure of one major airport and the affected passengers are sequentially relocated in delay-minimizing alternative itineraries within a predefined network, taking into account capacity constraints and allowing for ground transfers between airports. Third, the non-relocation rate and the aggregate delay are used as measures of network damage generated by the particular airport closure.

\subsection{Datasets}

The proposed method combines supply (schedules and seats) and demand data (passenger itineraries). The supply side is covered by a dataset of worldwide flight schedules during the first week of February 2013, for which the primary source is the OAG Schedules dataset. This time period was chosen as major airport closures in Europe are typically linked to adverse weather conditions during the North Hemisphere winter season ${ }^{4}$. After simple data processing, the supply dataset comprises 558,503 unique records of scheduled passenger flight departures for 755 airlines that offered 74.2 million seats across a network of 2,101 commercial airports. Each record indicates the operating airline, alliance membership (if applicable), flight number, origin and destination airport codes, aircraft type, number of seats, flight distance, and Universal Time Coordinated (UTC) departure and arrival times.

The demand side is covered by a Marketing Information Data Transfer (MIDT) dataset containing air passenger itineraries flown during February 2013. Each record contains information on the published airline, as well as the points of origin and destination, the connecting airports (up to two intermediate stops), and the number of passengers. The airports of origin and destination determine the market to which the passengers belong. Most markets can be served via different itineraries, depending on the points of connection. In total, the MIDT dataset contains 424,155 different itineraries in 135,078 directed markets, involving 47.1 million passengers, 441 airlines, and 2,150 airports (454 from the European Economic Area). Table 1 shows the distribution of this passenger demand by geographical

\footnotetext{
${ }^{4}$ An additional simulation was run for August 2013 in order to discuss the robustness of our results.
} 
markets. The largest market served by the European airport network is the intra-EEA, which amounts to $56.4 \%$ of its total passenger traffic. When non-EEA countries are also considered, the total share of intra-European traffic rises to $70.3 \%$. Of the remaining network traffic, $28,6 \%$ is devoted to linking Europe with the rest of the world, with the most important destinations being Asia-Pacific and North America. The remaining 1.1\% of passengers make use of European airports as gateways during their journeys between other continents. Note that Europe has a small presence in each continent pair, except the intra-American ones.

Table 1. Distribution of passenger demand by geographical markets (February 2013)

\begin{tabular}{|c|c|c|c|c|c|c|c|}
\hline (passengers travelling between) & $E \boldsymbol{E A}$ & $\begin{array}{r}\text { Rest of } \\
\text { Europe } \\
\text { (non-EEA) }\end{array}$ & Africa & Asia-Pacific & $\begin{array}{r}\text { Latin } \\
\text { merica and } \\
\text { Caribbean } \\
\end{array}$ & Middle East & North America \\
\hline$E E A$ & $26,585,156$ & $2,593,487$ & $2,268,371$ & $3,201,116$ & $1,406,508$ & $1,704,083$ & $2,494,909$ \\
\hline Rest of Europe (non-EEA) & & $3,949,195$ & 137,187 & $1,323,383$ & 83,527 & 672,892 & 204,223 \\
\hline Africa & & & 5,401 & 20,580 & 7,783 & 20,833 & 79,903 \\
\hline Asia-Pacific & & & & 11,892 & 36,349 & 19,526 & 134,450 \\
\hline Latin America and Caribbean & & & & & 0 & 26,243 & 0 \\
\hline Middle East & & & & & & 1,698 & 108,486 \\
\hline North America & & & & & & & 0 \\
\hline
\end{tabular}

Source: MIDT, own elaboration. Note: EEA: European Economic Area.

The original sources of information for the MIDT dataset are Global Distributions Systems (GDSs) such as Galileo, Sabre, or Amadeus, among others. According to ARG (2013), 44\% of all bookings of major airlines were done through GDSs in 2012. The proportion increases to $55 \%$ for network airlines, while low-cost carriers (LCCs), that prefer direct sales, only get $16 \%$ of their bookings via GDSs. This imbalance is an important limitation of the original dataset, as low-cost carriers may be underrepresented. In order to correct that, the provider of our data (OAG Traffic Analyser) adjusted the market figures using mathematical algorithms based on frequencies and supplied seats in each flight sector. The reliability of these adjustments, in terms of LCC representation, can be judged by calculating the airline market shares in the intra-EEA market that result from our adjusted data. The combined market share of LCCs is approximately $44 \%$, which is similar to the estimate provided by the European Commission for the common market in 2013 (EC, 2014b). Other past studies have also used this dataset for connectivity purposes (e.g, Suau-Sánchez et al., 2014, 2015).

Finally, the proposed method requires of three additional datasets: 1) a full list of alliance, codeshare, and interline partners for each published airline in the MIDT file. Alliance membership is broadly defined to include subsidiaries of member airlines that are not specifically named as affiliate members. ${ }^{5}$ This information was obtained both from OAG and the airlines' websites; 2) Airport-specific minimum connecting times for the 250 busiest airports in terms of connecting traffic ${ }^{6}$, including around 68,000 airline-specific exceptions. This was obtained from the OAG Connections Analyser; and 3) Minimum ground transfer times between the 50 largest airports in the European network and their potential surrogates. The surrogates are defined as the airports located less than $130 \mathrm{~min}$ of uncongested $\mathrm{road} / \mathrm{rail}$ transfer from a given airport. This represents the best road/rail travel time corresponding to the shortest scheduled flights at Europe's largest airports. The goal is to prevent road/rail transport to become a full alternative to air travel within the context of this paper. The travel times were easily obtained by using Google Maps.

\subsection{Creating the baseline scenario}

Although the MIDT dataset provides information on passenger itineraries, it does not indicate the actual flights taken by the passengers nor their travel times. Therefore, there is need to match each MIDT record with flight schedules from the OAG dataset in order to create a

\footnotetext{
${ }^{5}$ For example, Vueling is considered part of the Oneworld network for the purposes of passenger recovery.

${ }^{6}$ This sample covers $95 \%+$ of passengers connections in the MIDT file.
} 
baseline scenario. Due to the difference in time spans (demand data is for a month and schedules are for a week), the first step is to adjust the MIDT data in order to account for one week's traffic (dividing passengers by four).

Table 2. Sample MIDT record ( $1^{\text {st }}$ week of February 2013)

\begin{tabular}{llllll}
\hline Published Airline & Origin & Gateway 1 & Gateway 2 & Destination & Passengers \\
\hline IB (Iberia) & LPA (Gran Canaria) & MAD (Madrid) & - & LHR (Heathrow) & 70 \\
\hline
\end{tabular}

For each adjusted MIDT record (Table 2), a search is made in the OAG file for all relevant flights (i.e. LPA to MAD and MAD to LHR) that were operated by either the published airline or any of its partners during the sample week. In case the airline filters do not return any matches, the search is broadened to include all airlines ${ }^{7}$.

If the itinerary involves more than one sector, flight connections are built on the following restrictions, adapted from Grosche (2009): a) the published minimum connecting times must be met, b) the maximum connecting time is arbitrarily set at one hour above the shortest valid connection time $\left.{ }^{8}, \mathrm{c}\right)$ passengers on each first-leg flight always prefer the alternative with the shortest travel time, and d) passengers on each final-leg flight also prefer the shortest travel times. The process is illustrated in Table 3 below. The four shortest connections are discarded because they do not meet the minimum connecting times set by Madrid airport for DomesticInternational transfers between the sample airlines. As a result, the shortest valid connection is $65 \mathrm{~min}$ and the maximum connecting time is set as $125 \mathrm{~min}$. The third condition discards all the underlined connections because a shorter alternative is available for the first-leg passengers. Finally, we also discard the connection in italics (18:05-20:10) because the second-leg flight can be reached by a later arrival.

Table 3. Selected flight connections for the sample MIDT record (only Monday flights)

\begin{tabular}{|c|c|c|c|c|c|c|c|c|c|c|c|c|c|c|}
\hline \multicolumn{7}{|c|}{ Connecting times (min) } & \multicolumn{8}{|c|}{ MAD-LHR } \\
\hline \multirow{6}{*}{ 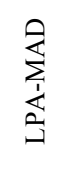 } & arrival\departure & $10: 45$ & $12: 40$ & $13: 35$ & $14: 20$ & $14: 55$ & 15:00 & $15: 55$ & $16: 50$ & $17: 10$ & $18: 30$ & $20: 10$ & $20: 45$ & $06: 45^{+1}$ \\
\hline & $10: 30$ & 15 & 130 & 185 & 230 & 265 & 270 & 325 & 380 & 400 & 480 & 580 & 615 & 1,215 \\
\hline & $14: 50$ & & & & & 5 & 10 & 65 & 120 & 140 & 220 & 320 & 355 & 955 \\
\hline & 18:05 & & & & & & & & & & 35 & 125 & 170 & 770 \\
\hline & 19:00 & & & & & & & & & & & 70 & $\underline{105}$ & 705 \\
\hline & $22: 25$ & & & & & & & & & & & & & 500 \\
\hline
\end{tabular}

The outcome of this selection process will be a baseline scenario in which passengers take the best connections available, leading to minimum travel times. We acknowledge that this is somewhat unrealistic in the sense that passengers may trade off longer connection times for cheaper fares or more convenient flight times, thus spending more time at the hub airport than the minimum necessary to complete their trip. On the other hand, these "inflated" connection times may compromise the measures of network damage by introducing a substantial element of travel time savings as a result of passenger rescheduling (i.e., a passenger with a 6-hour extended connection at a closed hub may be given a 1-hour connection in an alternate airport instead). Hence, while a more complex modeling of passenger flight choice is slated for future research, for this initial application a "minimum travel time" baseline scenario is considered an appropriate benchmark to provide measures that can be easily interpreted.

Once the suitable flights (or flight combinations) are selected, the number of passengers in the MIDT record is distributed among them according to seat capacity (Table 4), which is determined by the minimum number of seats across all sectors. The proportion of passengers

\footnotetext{
${ }^{7}$ If there were no scheduled flights for any of the relevant sectors, the MIDT record is discarded.

${ }^{8}$ This is meant to allow for some variability in connection times across the sample week. The goal is to prevent all passengers being allocated to the best weekly connection, which, in early simulations, usually led to capacity problems and important computational costs. Changing this window to 2 hours increases the sample-wide average connecting time only in 2.5\% (approx. 3-4 min) due to the effect of other restrictions.
} 
allocated to each travel option is equal to the proportion of its seat capacity to total capacity9 Total travel times for each flight combination that has received at least one passenger are added to the baseline scenario for the analysis of network vulnerability.

Table 4. Allocation of demand to flight combinations and generation of travel times for the baseline scenario

\begin{tabular}{|c|c|c|c|c|c|c|c|c|c|c|c|c|c|c|}
\hline \multirow[b]{2}{*}{ ID } & \multirow[b]{2}{*}{ Day } & \multicolumn{5}{|c|}{ Flight 1: LPA-MAD } & \multicolumn{5}{|c|}{ Flight 2: MAD-LHR } & \multicolumn{3}{|c|}{ Full itinerary } \\
\hline & & Airline & Flight No. & Dep. & Arr. & Seats & Airline & Flight No. & Dep. & Arr. & Seats & $\begin{array}{c}\text { Seat } \\
\text { capacity }\end{array}$ & Pax. & $\begin{array}{c}\text { Travel } \\
\text { Time }(m)\end{array}$ \\
\hline 1 & Mon & $\mathrm{I} 2$ & 3925 & $11: 15$ & $14: 50$ & 150 & IB & 3166 & $15: 55$ & $17: 20$ & 200 & 150 & 4 & 365 \\
\hline 2 & Mon & IB & 823 & $15: 10$ & 19:00 & 200 & BA & 463 & $20: 10$ & $21: 30$ & 254 & 200 & 5 & 380 \\
\hline 3 & Tue & $\mathrm{I} 2$ & 3925 & $11: 15$ & $14: 50$ & 150 & IB & 3166 & $15: 55$ & $17: 20$ & 342 & 150 & 4 & 365 \\
\hline$\ldots$ & $\ldots$ & $\ldots$ & $\ldots$ & $\ldots$ & $\ldots$ & $\ldots$ & $\ldots$ & $\ldots$ & . & $\ldots$ & $\ldots$ & $\ldots$ & $\ldots$ & \\
\hline 17 & Sun & IB & 823 & $15: 10$ & 19:00 & 200 & BA & 463 & $20: 10$ & $21: 30$ & 254 & 200 & 5 & 380 \\
\hline & & & & & & & & & & & Total & 2,875 & 70 & \\
\hline
\end{tabular}

After a first round of processing, the records in the baseline scenario are aggregated by flight number and departure date in order to check whether the number of passengers in all origin/destination markets assigned to each individual flight does not exceed the seat capacity of the aircraft. Passengers over capacity are taken out of the baseline scenario ${ }^{10}$ and brought into new rounds of processing with updated seat capacities in the OAG file ${ }^{11}$. For this paper, three sequential rounds were enough to ensure that $95.8 \%$ of all passengers were allocated.

\begin{tabular}{lrr} 
Table 5. Outcome of the passenger allocation process \\
\hline Status & Passengers & Share \\
\hline Allocated-first round & $10,915,521$ & $92.70 \%$ \\
Allocated-second round & 313,914 & $2.67 \%$ \\
Allocated-third round & 56,344 & $0.48 \%$ \\
Total Allocated & $11,285,779$ & $95.85 \%$ \\
\hline No Schedules & 318,840 & $2.71 \%$ \\
No valid Connections & 59,609 & $0.51 \%$ \\
Over Capacity & 110,683 & $0.94 \%$ \\
Total Passengers & $11,774,911$ & $100.00 \%$ \\
\hline \hline Allocated nassengers onlv & & \\
\hline \hline Non-ston trins & 8.883 .646 & $78.72 \%$ \\
Connecting trips & $2,402,133$ & $21.28 \%$ \\
\hline 1-stop & $2,326,103$ & $96.83 \%$ \\
2-stops & 76,030 & $3.17 \%$ \\
\hline Inline & $1,487,645$ & $61.93 \%$ \\
Intra-alliance & 563,978 & $23.48 \%$ \\
Inter-alliance & 67,413 & $2.81 \%$ \\
Other interline & 283,097 & $11.79 \%$ \\
\hline
\end{tabular}

The remainder of passenger bookings (4.2\%) had to be discarded for different reasons (See Table 5): $2.7 \%$ did not have any schedules for at least one of its sectors, $0.9 \%$ were over capacity, and $0.5 \%$ of the proposed itineraries did not match to any valid connections. These lost records can be explained by the fact that, while OAG schedules belong to the actual week under study, MIDT traffic represents an average week in February. Therefore, it may include itineraries flown in any of the other weeks. Further exploration of the data indicates that $85 \%$ of connecting trips in our sample are predicted to have been served entirely within the respective alliances, with the remaining 15\% relying upon individual interlining and codeshare agreements signed by the carriers, regardless of their alliance membership.

Finally, in order to assess the reliability of this stage, we check the predicted load factors in intra-European flights that result from our baseline scenario and compare them with the actual ones reported for February 2013 by the Association of European Airlines (AEA) and the largest individual carriers. These are reported in Table 6 . The predicted load factors for

\footnotetext{
${ }^{9}$ In order not to lose or gain passengers due to rounding, results are rounded up or down randomly until all passengers in the MIDT record were allocated, giving preference to the fastest flight combinations.

${ }^{10}$ The passenger numbers in those records involving flights over capacity are scaled down in the same exact proportion needed to bring the overall passengers to the level of full capacity.

${ }_{11}$ Full flights are also taken out of the OAG file, leading to different flight connections being built in the second- and subsequent stages. Once the popular best-daily-connections are likely to be full, the excess demand is more likely to be allocated to longer off-peak connections (i.e. the 10:30-12:40 transfer in Table 3).
} 
our week are roughly similar to the actual ones for the entire month, and successfully discriminate between carriers, with LCCs having largest load factors than network airlines.

Table 6. Predicted load factors in intra-European routes (1st week of February 2013)

\begin{tabular}{|c|c|c|c|c|}
\hline \multirow{2}{*}{$\begin{array}{l}\text { Association of European Airlines } \\
(A E A) \text { Members }\end{array}$} & \multirow{2}{*}{ ASK (million) } & \multirow{2}{*}{ RPK (million) } & \multicolumn{2}{|c|}{ Load Factor } \\
\hline & & & Predicted & Reported Feb-2013 \\
\hline Europe Domestic & $1,236.3$ & 757.8 & $61.3 \%$ & $66.6 \%$ \\
\hline Europe Cross-border & $4,633.7$ & $3,126.8$ & $67.5 \%$ & $69.3 \%$ \\
\hline Europe Total & $5,870.0$ & $3,884.7$ & $66.2 \%$ & $68.7 \%$ \\
\hline \multicolumn{5}{|l|}{ Major Carriers } \\
\hline Ryanair & $1,475.3$ & $1,097.0$ & $74.4 \%$ & $77.0 \%$ \\
\hline Easyjet & $1,083.9$ & 939.4 & $86.7 \%$ & $90.5 \%$ \\
\hline Air France-KLM Group & $1,132.6$ & 775.8 & $68.5 \%$ & $68.6 \%$ \\
\hline Lufthansa Passenger Airlines & $1,036.6$ & 685.1 & $66.1 \%$ & $66.0 \%$ \\
\hline SAS group & 456.4 & 288.0 & $63.1 \%$ & $66.9 \%$ \\
\hline International Airlines Group & 853.4 & 569.4 & $66.7 \%$ & $69.5 \%$ \\
\hline Norwegian Air Shuttle & 436.5 & 330.2 & $75.6 \%$ & $78.3 \%$ \\
\hline Air Berlin & 488.1 & 402.7 & $82.5 \%$ & $85.3 \%$ \\
\hline
\end{tabular}

The datasets with the baseline scenario and the predicted load factors for all individual flights are brought forward to the next stage.

\subsection{Airport closures and passenger rescheduling}

An airport closure is characterised by a vector including the airport code and the times of beginning and end of the closure. The passenger itineraries from the baseline scenario and the predicted load factors are checked against the parameters of the airport closure. Using a similar approach than Janic (2015), all flights scheduled to arrive at ${ }^{12}$ or depart from a closed airport are labelled as "OFF". Of all remaining flights, those already at full capacity are labelled as "FULL" and the rest are "ON". For each record in the baseline scenario, the itineraries to be considered for rescheduling include: 1) all "OFF" flights, 2) all "ON" or "FULL" flights departing after an "OFF" flight (i.e. passengers are rescheduled to the end of their trip), 3) all "ON" or "FULL" flights preceding an "OFF" flight but still departing within the period of closure. ${ }^{13}$ Every disrupted demand record is compiled in a rescheduling matrix that indicates the number of passengers, the first flight in their itinerary to be rescheduled, and the final destination of their trip. This matrix is sorted by the departure time of the indicated flight in order to establish the sequence in which passengers will be relocated.

From the perspective of the airlines, two different passenger recovery options are considered: 1) relocation via the remaining flights in the affected airline's alliance network, where applicable ${ }^{14}$, and 2) unrestricted relocation (passengers can be relocated in suitable flights operated by all airlines). For simplicity, only remaining "ON" flights can be used for passenger recovery and all retain their original schedules ${ }^{15}$. In addition, there is the possibility

\footnotetext{
${ }^{12}$ For simplicity, we do not consider the implications of being caught by the closure mid-flight. However, since the closures used in this paper start at midnight, the number of flights affected by this is relatively small.

${ }^{13}$ For example, if the itinerary is $\mathrm{A} \rightarrow \mathrm{B} \rightarrow \mathrm{C} \rightarrow \mathrm{D}$ and airport $\mathrm{C}$ is closed, the passengers will be considered for rescheduling when they are at airport $\mathrm{A}$ if the closure is already known at the time of their $\mathrm{A} \rightarrow \mathrm{B}$ departure. This gives the airline the opportunity to look for an alternative routing as soon as possible in order to minimize delay (note that this optimal routing may end up including the $\mathrm{A} \rightarrow \mathrm{B}$ flight anyway). If the $\mathrm{A} \rightarrow \mathrm{B}$ flight departs before the beginning of the closure of $\mathrm{C}$, then the passengers will be considered for rescheduling when they are at $\mathrm{B}$. Responsibility for relocation is given to the airline that operates the first flight in the affected sequence.

${ }^{14}$ For non-alliance members, the relocation is made via the remaining flights in the affected airline's own flight network (including their parent airline and subsidiaries, where applicable). Airline-specific IROPS guidelines, which specify the preferred partners for flight relocation under irregular operations, were not implemented due to computational restrictions.

${ }^{15}$ In the absence of data on aircraft registration numbers, there is no practical way of determining the additional flights that would need to be cancelled due to the aircraft being grounded in the closed airport. The introduction of congestion and schedule delays is left for future research.
} 
of transferring to other airports by ground transport with the objective to make flight connections or end the journey. The model, however, does not contemplate the option of entirely substituting air travel by ground travel. This is consistent with the current goal of measuring how well the European air transport network, taken as an isolated component of the overall European transport network, is able to absorb major shocks.

Table 7. Rules for the calculation of directed time distances

\begin{tabular}{|c|c|c|c|}
\hline $\begin{array}{l}\text { Origin } \\
\text { Node }\end{array}$ & $\begin{array}{l}\text { Destination } \\
\text { Node }\end{array}$ & Conditions & Time distance \\
\hline $\begin{array}{l}\text { ON or FULL } \\
\text { flight }\end{array}$ & $\begin{array}{l}\text { ON } \\
\text { flight }\end{array}$ & $\begin{array}{l}\text { The origin flight can connect to any future onward journey } \\
\text { that departs from its destination airport or from a valid } \\
\text { surrogate of the latter. In both cases, the recovery networks } \\
\text { of both flights must be compatible (i.e. alliance or } \\
\text { unrestricted), there must be enough connecting time, and the } \\
\text { onward flight must not come back to the initial airport. }\end{array}$ & $\begin{array}{l}\text { = Departure Time Destination flight - } \\
\text { Departure Time Origin flight }\end{array}$ \\
\hline $\begin{array}{l}\text { ON or FULL } \\
\text { flight }\end{array}$ & $\begin{array}{l}\text { OFF or FULL } \\
\text { flight }\end{array}$ & $\begin{array}{l}\text { An "OFF" or "FULL" is not a valid onward journey for } \\
\text { passengers that are being relocated from other flights. }\end{array}$ & Not defined \\
\hline $\begin{array}{l}\text { ON or FULL } \\
\text { flight }\end{array}$ & $\begin{array}{l}\text { GRT or END } \\
\text { node }\end{array}$ & $\begin{array}{l}\text { There is always a time distance if the END/GRT airport is } \\
\text { the destination of the origin flight. }\end{array}$ & $\begin{array}{l}=\text { Arrival Time Origin flight }- \text { Departure } \\
\text { Time Origin flight }\end{array}$ \\
\hline $\begin{array}{l}\text { OFF } \\
\text { flight }\end{array}$ & $\begin{array}{l}\text { ON } \\
\text { flight }\end{array}$ & $\begin{array}{l}\text { The stranded passengers can connect to any future onward } \\
\text { journey that departs from a valid surrogate of the closed } \\
\text { airport or from the latter when it reopens, provided the } \\
\text { recovery networks of both flights are compatible and there is } \\
\text { enough connecting time. }\end{array}$ & $\begin{array}{l}\text { = Departure Time Destination flight - } \\
\text { Departure Time Origin flight }\end{array}$ \\
\hline $\begin{array}{l}\text { OFF } \\
\text { flight }\end{array}$ & $\begin{array}{l}\text { OFF or FULL } \\
\text { flight }\end{array}$ & $\begin{array}{l}\text { An "OFF" or "FULL" flight is not a valid onward journey } \\
\text { for passengers that are being relocated from other flights. }\end{array}$ & Not defined \\
\hline $\begin{array}{l}\text { OFF } \\
\text { flight }\end{array}$ & $\begin{array}{l}\text { GRT or END } \\
\text { node }\end{array}$ & $\begin{array}{l}\text { Two consecutive ground transfers are not allowed. An END } \\
\text { node can only be reached from an "ON" or "FULL" origin } \\
\text { flight or by means of a ground transfer. }\end{array}$ & Not defined \\
\hline GRT node & - & $\begin{array}{l}\text { There is a time distance if and only if the destination node is } \\
\text { an END node of a valid surrogate of the GRT airport. }\end{array}$ & $\begin{array}{l}=\text { Ground Transfer Time between GRT and } \\
\text { END airports (replaced by zero if both } \\
\text { airports serve the same city) }\end{array}$ \\
\hline
\end{tabular}

The search for alternative routings for passenger recovery will be governed by the objective of delay-minimization as it is common under irregular airline operations (Barnhart, 2009) ${ }^{16}$. To that end, a standard shortest-path-length algorithm will be adapted to our case study and applied on a directed distance matrix where the distance between origin nodes (rows) and destination nodes (columns) is expressed in time units. The main origin and destination nodes of this matrix will be all flights in the load factors dataset that depart between the time of the earliest flight in the rescheduling matrix and an arbitrary period of 24 hours after the end of the airport closure ${ }^{17}$. Origin flight nodes indicate points in time where passengers are expected to make a flight departure. One additional origin node is added for every airport in the network labelled "GRT (ground transfer)", which represents the possibility of departing from an airport by road/rail in order to complete the last travel segment. Destination flight nodes indicate points in time where passengers have reached the next flight departure in their journey. Two additional destination nodes are added for every airport in the network labelled "GRT" and "END". The first denotes a passenger arriving from a flight to immediately leave by $\mathrm{road} / \mathrm{rail}$ in order to complete the last travel segment, and the second denotes a passenger that reaches the final destination in its journey.

\footnotetext{
${ }^{16}$ Focusing on passenger delays is consistent with the implicit use of travel times as key performance indicator by the European Commission in defining long-term goals in the area of aviation: "By 2050, 90\% of travels involving air transport within Europe can be completed in 4 hours door-to-door" (EC, 2014a).

17 This is set up mainly for computational purposes (it restricts the size of the distance matrix) and defines a limit in the depth of search for suitable future flights to relocate the passengers. By setting this parameter at 24 hours after the closure ends, stranded passengers that cannot be relocated on the same day could potentially be assigned to the same original itinerary after the airport reopens the following day.
} 
The time distances within the matrix are calculated following the set of rules detailed in Table 7, which take into account the status of the origin and destination flight nodes. Published minimum connecting times are used to generate valid flight connections in this stage as well, including official inter-airport transfer times (e.g. Heathrow-Gatwick) ${ }^{18}$. No ground transfer times will be added between surrogate airports in the same city.

Once the initial distance matrix has been constructed, the rescheduling algorithm finds the optimal alternative routing for the disrupted passengers in a dynamic and iterative process (Table 8). Capacity constraints are taken into account: if there is no spare capacity to allocate all disrupted passengers in their new itinerary, the excess passengers are taken aside and relocated in the next iteration using an updated distance matrix that reflects the changes in capacity. Any passenger that remains unallocated at the end of the process is flagged as such.

Table 8. Algorithm for passenger rescheduling

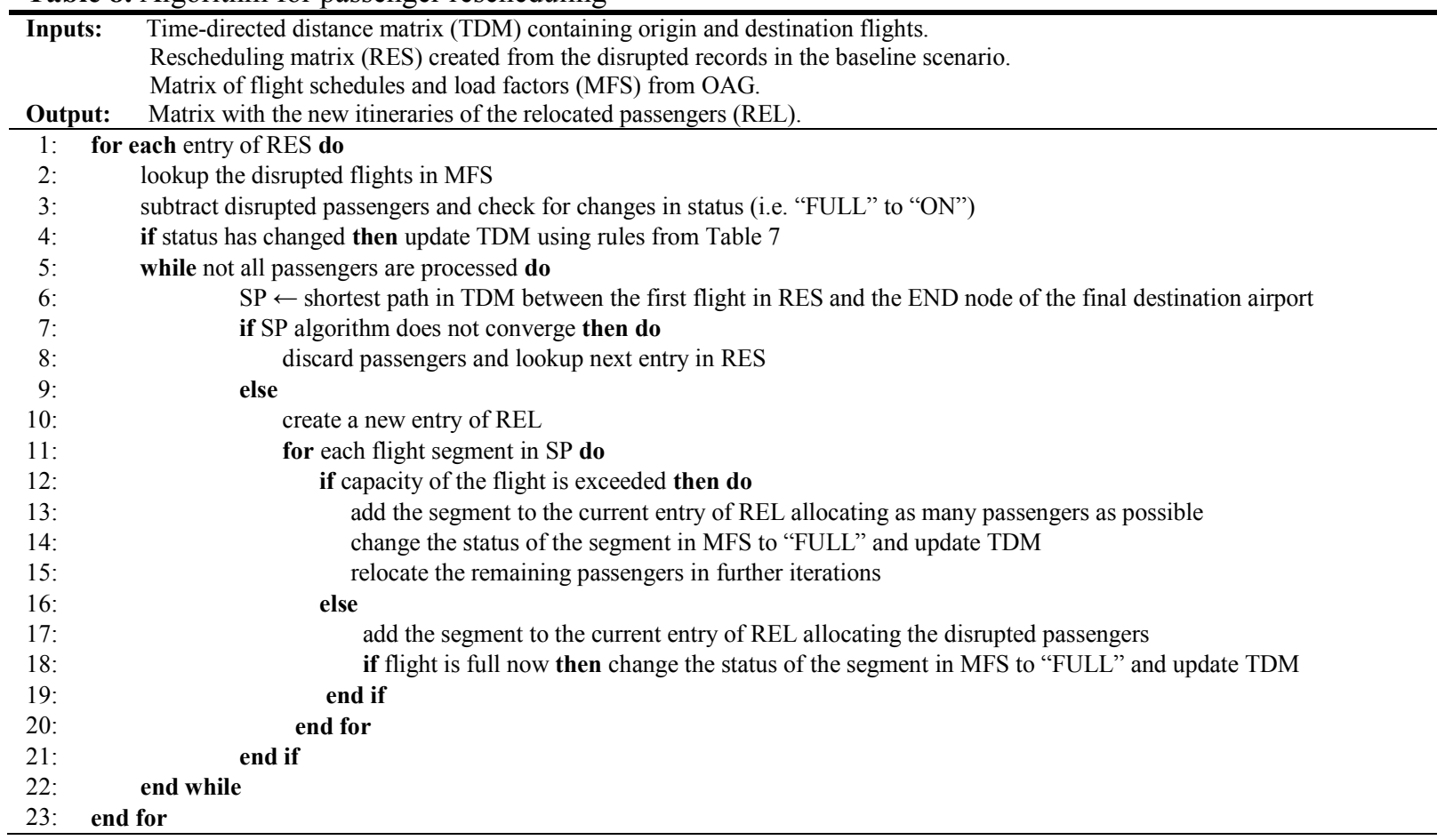

The calculation of shortest-path itineraries made use of the iGraph library in R. This employs the well-known Dijkstra algorithm, which performs an exhaustive search ${ }^{19}$ that ensures that, if anything, a shortest path is always returned.

\subsection{Measuring vulnerability and airport criticality}

In total, 100 individual airport closure scenarios are run, four for each of the 25 busiest European airports (Table 9). The closures last 24 hours (00:00-24:00 UTC) and happen either Monday or Friday, which are considered the most critical days in terms of "weekday" and "weekend" traffic. In the Monday case, running both alliance and unrestricted options allows us to assess how close the airline alliances that dominate the major European hubs come to

\footnotetext{
${ }^{18}$ Since there are no official inter-airport transfer times for all surrogate airport pairs in the sample, artificial values were constructed. We observed that, on average, inter-airport transfers allow for three times the length of the uncongested ground transfer plus the standard transfer time for the type of connection.

${ }^{19}$ Despite the relatively high number of nodes (around 64,000 scheduled departures), the shortest-paths problem can be easily addressed using iGraph library in R due to the low density of the distance matrix (0.0038). A binary-heap implementation of Dijkstra's algorithm makes the time complexity logarithmic in the number of links, i.e. $\mathrm{O}(\mathrm{L} * \log (\mathrm{L})+\mathrm{N})$, where $\mathrm{N}, \mathrm{L}$ are the total number of nodes and links in the network, respectively.
} 
offering the globally optimal solutions (exclusively in terms of travel time) to their disrupted passengers. An extra scenario without seat capacity constraints will also be run.

Table 9. Top 25 busiest European airports (estimated traffic for $1^{\text {st }}$ Week of February 2013)

\begin{tabular}{|c|c|c|c|c|c|c|c|c|c|c|c|}
\hline \multirow[t]{2}{*}{ Airport } & \multicolumn{3}{|c|}{ Passengers (all markets) } & \multicolumn{3}{|c|}{ Passengers (intra-EEA) } & \multicolumn{4}{|c|}{ Distribution of passenger departures } & \multirow{2}{*}{$\begin{array}{l}\text { \% inter- } \\
\text { alliance }\end{array}$} \\
\hline & $O D$ & Conn. & Total & $O D$ & Conn. & Total & OneW & StarAll & Skyteam & Other & \\
\hline London Heathrow (LHR) & 903,181 & 156,133 & $1,059,314$ & 397,387 & 24,478 & 421,865 & $57.4 \%$ & $20.2 \%$ & $6.4 \%$ & $16.0 \%$ & $5.6 \%$ \\
\hline Paris $(\mathrm{CDG})$ & 600,521 & 172,802 & 773,323 & 312,842 & 35,245 & 348,087 & $5.7 \%$ & $11.3 \%$ & $65.4 \%$ & $17.5 \%$ & $6.0 \%$ \\
\hline Frankfurt (FRA) & 422,106 & 221,392 & 643,498 & 211,358 & 63,908 & 275,266 & $6.3 \%$ & $76.3 \%$ & $5.5 \%$ & $11.9 \%$ & $7.2 \%$ \\
\hline Istanbul Ataturk (IST) & 423,722 & 189,246 & 612,968 & 0 & 1,208 & 1,208 & $1.4 \%$ & $78.7 \%$ & $4.4 \%$ & $15.6 \%$ & $2.5 \%$ \\
\hline Madrid (MAD) & 475,918 & 103,879 & 579,797 & 368,823 & 39,602 & 408,425 & $51.8 \%$ & $8.6 \%$ & $19.1 \%$ & $20.6 \%$ & $8.2 \%$ \\
\hline Amsterdam (AMS) & 414,963 & 157,518 & 572,481 & 272,269 & 45,157 & 317,426 & $5.4 \%$ & $8.7 \%$ & $70.3 \%$ & $15.6 \%$ & $6.4 \%$ \\
\hline Munich (MUC) & 371,358 & 118,599 & 489,957 & 269,747 & 65,870 & 335,617 & $13.1 \%$ & $73.7 \%$ & $4.4 \%$ & $8.8 \%$ & $3.6 \%$ \\
\hline Barce & 442,452 & 14,819 & 457,271 & 372,342 & 12,313 & 384,655 & $40.6 \%$ & $13.7 \%$ & $11.6 \%$ & $34.1 \%$ & $2.4 \%$ \\
\hline London Gatwick (LGW) & 439,171 & 14,385 & 453,556 & 337,820 & 6,487 & 344,307 & $17.7 \%$ & $2.6 \%$ & $1.4 \%$ & $78.3 \%$ & $3.8 \%$ \\
\hline Rome Fuimicino (FCO) & 363,363 & 69,602 & 432,965 & 261,918 & 34,293 & 296,211 & $7.7 \%$ & $11.4 \%$ & $55.6 \%$ & $25.3 \%$ & $6.0 \%$ \\
\hline Paris Orly (ORY) & 393,225 & 20,315 & 413,540 & 293,045 & 15,917 & 308,962 & $9.5 \%$ & $3.2 \%$ & $47.7 \%$ & $39.6 \%$ & $2.3 \%$ \\
\hline Moscow Dom. (DME) & 348,163 & 40,473 & 388,636 & 0 & 6 & 6 & $35.4 \%$ & $7.2 \%$ & $2.1 \%$ & $55.2 \%$ & $3.9 \%$ \\
\hline Moscow Sher & 276,968 & 75,973 & 352,941 & 0 & 319 & 319 & $0.4 \%$ & $1.5 \%$ & $90.9 \%$ & $7.2 \%$ & $3.9 \%$ \\
\hline Oslo (OSL) & 293,093 & 38,861 & 331,954 & 264,922 & 36,591 & 301,513 & $4.4 \%$ & $46.6 \%$ & $3.2 \%$ & $45.8 \%$ & $4.9 \%$ \\
\hline (CPH) & 270,369 & 48,908 & 319,277 & 213,933 & 39,527 & 253,460 & $8.3 \%$ & $56.7 \%$ & $4.9 \%$ & $30.2 \%$ & $7.1 \%$ \\
\hline Zurich (ZRH) & 246,771 & 66,517 & 313,288 & 165,353 & 27,967 & 193,320 & $12.4 \%$ & $75.1 \%$ & $4.9 \%$ & $7.6 \%$ & $9.6 \%$ \\
\hline Stockholm (ARN) & 275,928 & 26,408 & 302,336 & 229,491 & 23,853 & 253,344 & $9.1 \%$ & $56.3 \%$ & $5.2 \%$ & $29.3 \%$ & $5.3 \%$ \\
\hline Geneva (GVA) & 278,612 & 4,638 & 283,250 & 222,724 & 2,982 & 225,706 & $8.8 \%$ & $30.6 \%$ & $11.1 \%$ & $49.6 \%$ & $3.8 \%$ \\
\hline Dus & 266,593 & 16,546 & 283,139 & 198,081 & 9,525 & 207,606 & $35.7 \%$ & $44.3 \%$ & $6.9 \%$ & $13.0 \%$ & $3.1 \%$ \\
\hline Milano Malpensa (MXP) & 267,615 & 4,070 & 271,685 & 172,583 & 1,201 & 173,784 & $10.8 \%$ & $25.3 \%$ & $12.3 \%$ & $51.6 \%$ & $3.3 \%$ \\
\hline Dublin (DUB) & 255,230 & 9,504 & 264,734 & 220,012 & 5,556 & 225,568 & $5.2 \%$ & $5.2 \%$ & $4.8 \%$ & $84.8 \%$ & $8.4 \%$ \\
\hline Bru & 238,806 & 23,881 & 262,687 & 158,662 & 10,150 & 168,812 & $8.7 \%$ & $59.1 \%$ & $8.3 \%$ & $23.9 \%$ & $6.9 \%$ \\
\hline Vie & 209,851 & 52,360 & 262,211 & 144,021 & 20,321 & 164,342 & $18.6 \%$ & $67.5 \%$ & $5.7 \%$ & $8.3 \%$ & $4.7 \%$ \\
\hline London Stansted (STN) & 258,752 & 623 & 259,375 & 249,679 & 523 & 250,202 & $0.9 \%$ & $2.9 \%$ & $0.0 \%$ & $96.2 \%$ & $1.8 \%$ \\
\hline Manchester (MAN) & 251,335 & 5,293 & 256,628 & 171,173 & 3,734 & 174,907 & $10.0 \%$ & $14.6 \%$ & $5.8 \%$ & $69.6 \%$ & $5.3 \%$ \\
\hline
\end{tabular}

Due to the fact that all the disruptions modelled affect only one component of the network (the closed airport), the measure of "conditional criticality" under each closure scenario will be used also as a measure of "conditional vulnerability" of the entire network ${ }^{20}$. In our case study, this is measured by the non-relocation rate (the proportion of passengers for which an alternative itinerary was not found within the search period - 24 hours after the closure ends) and, also, by the accumulated delay experienced by the disrupted passengers. For those relocated, the total delay is the difference between the journey times of the baseline and rescheduled itineraries. For non-relocated passengers, the total delay is measured as the difference between their baseline departure and the end of the search period. Separate measures of airport criticality will be provided for the intra-EEA markets and we will also report the airports that serve the largest amounts of relocated traffic in each closure scenario.

Finally, the resulting ranking of airport criticality will be compared with three well-known topological indicators - degree centrality, closeness, and betweenness centrality - in order to establish a link between our results and the previous literature. Degree centrality $\left(D_{i}\right)$ is calculated as the total number of destinations served by airport $i$. Closeness $\left(C_{i}\right)$ is the inverse of the sum of the distances between airport $i$ and all other airports in the network:

$$
C_{i}=\frac{1}{\sum_{j} \operatorname{distance}(i, j)} \text {. }
$$

Betweeness centrality $\left(\mathrm{B}_{i}\right)$ is calculated as follows:

$$
B_{i}=\sum_{j \neq i \neq k} \frac{\sigma_{j k(i)}}{\sigma_{j k}}
$$

where $\sigma_{j k}$ are the total number of shortest paths (measured in graph distance - number of links between two nodes) from airport $j$ to airport $k$ and $\sigma_{j k(i)}$ is the number of those paths that pass

\footnotetext{
${ }^{20}$ From now on, "conditional vulnerability" and "conditional criticality" will be simply referred as vulnerability and criticality, respectively.
} 
through airport $i$. Both $C_{i}$ and $B_{i}$ will be calculated over unweighted networks and normalized between $[0,1]$. The lack of degrees of freedom prevents us from carrying out a regression analysis, so our conclusions will be based on correlation coefficients. Further discussion of any drivers of airport criticality beyond network topology will be mostly exploratory and rely on ad-hoc indicators based on the simulation results.

\section{RESULTS AND DISCUSSION}

The simulation results are provided in Appendices A-E alongside a glossary of airport codes in Appendix F.

\subsection{Airport criticality vs. network topology}

Table 10 summarizes the simulation results for the Monday closure, under alliance recovery, and considering all markets (Appendix A). While the limited temporal scope of the measures provided (February 4-5, 2013) must always be borne in mind, it is possible to obtain interesting conclusions by ranking the airports according to several dimensions. The first one is the number of disrupted passengers (dpax), which is topped by major airports; i.e., Heathrow, Paris-CDG, and Istanbul (it is estimated to surpass Frankfurt in terms of passenger traffic on the sample day). From the point of view of passenger recovery, however, important differences can be found within the largest European hubs. The airlines affected by the closure of Istanbul Ataturk are able to relocate $61 \%$ of disrupted passengers within their own alliances $(\%$ reloc $)$. The relocation rate increases to around $72 \%$ for Heathrow and Paris, while Frankfurt stands out with the highest relocation rate in the entire sample at $86.9 \%$. Amsterdam is marginally below $60 \%$ and other major airports such as Domodedovo (39.5\%), Milano Malpensa (43.5\%), Gatwick (38.9\%), or Barcelona (46.2\%) are among the worstranked. Of course, relocation rates are capped by the amount of inter-alliance traffic, which cannot be relocated as per the model restrictions. However, by comparing these relocation rates with the inter-alliance traffic shares reported in Table 9 - all below $10 \%$ - , it is clear that the performance of the latter airports is very poor. The quality of the alternative itineraries is a further concern in Barcelona, as relocated passengers would experience, on average, increases of more than $400 \%$ in travel times over the best available itineraries from the baseline scenario $(\Delta a v t \%)$. A similar effect is predicted for Stansted Airport. On the contrary, the airlines operating at Frankfurt should be able to provide the best alternative itineraries within their own alliances, with an average delay of only $69.5 \%$ over the baseline travel times. The next best in that category would be Paris-CDG, with a $113.2 \% \Delta a v t \%$. The aggregate delay experienced by both relocated and non-relocated passengers (aggdel') indicates that the most critical airports in the European network during the sample period were Heathrow, Barcelona, and Istanbul with overall impacts ranging from 57 to 64 thousand passenger-days. Highest delays per passenger, nevertheless, are experienced in MoscowDME, Barcelona, and Milano Malpensa.

Table 10. Simulation results: Monday closure; alliance passenger recovery; all markets.

\begin{tabular}{|c|c|c|c|c|c|c|c|c|c|c|c|c|}
\hline \multirow{3}{*}{$\begin{array}{l}\text { Closed } \\
\text { Airport }\end{array}$} & \multicolumn{12}{|c|}{ All markets } \\
\hline & $d p a x$ & reloc & \%reloc & avt0 & avt1 & $\Delta a v t \%$ & non-reloc & aggdel $^{\prime}$ & $l^{\prime} / d p a x$ & $D i$ & $\mathrm{Ci}$ & $B i$ \\
\hline & & & & & & & & (pax-days) & (days) & & & \\
\hline Heathrow & 108,197 & 78,267 & $72.30 \%$ & 348 & 805 & $131.50 \%$ & 29,930 & 64,832 & 0.599 & 140 & 0.482 & 0.056 \\
\hline Barcelona & 64,825 & 29,954 & $46.20 \%$ & 174 & 884 & $408.80 \%$ & 34,871 & 62,718 & 0.967 & 107 & 0.420 & 0.016 \\
\hline Istanbul & 75,410 & 46,346 & $61.50 \%$ & 300 & 807 & $168.50 \%$ & 29,064 & 57,843 & 0.767 & 174 & 0.453 & 0.054 \\
\hline Gatwick & 59,929 & 23,329 & $38.90 \%$ & 162 & 385 & $137.80 \%$ & 36,600 & 55,821 & 0.931 & 107 & 0.416 & 0.017 \\
\hline Madrid & 68,386 & 42,442 & $62.10 \%$ & 239 & 807 & $237.20 \%$ & 25,944 & 52,684 & 0.770 & 126 & 0.448 & 0.031 \\
\hline Amsterdam & 63,250 & 37,744 & $59.70 \%$ & 319 & 765 & $139.80 \%$ & 25,506 & 47,370 & 0.749 & 170 & 0.475 & 0.057 \\
\hline Moscow DME & 46,649 & 18,428 & $39.50 \%$ & 235 & 502 & $114.10 \%$ & 28,221 & 46,952 & 1.006 & 112 & 0.416 & 0.055 \\
\hline Paris CDG & 78,532 & 56,417 & $71.80 \%$ & 322 & 687 & $113.20 \%$ & 22,115 & 44,758 & 0.570 & 178 & 0.488 & 0.087 \\
\hline Rome Fuimicino & 55,017 & 36,396 & $66.20 \%$ & 231 & 815 & $252.90 \%$ & 18,621 & 40,864 & 0.743 & 110 & 0.444 & 0.019 \\
\hline Paris Orly & 55,448 & 32,541 & $58.70 \%$ & 131 & 425 & $224.40 \%$ & 22,907 & 38,436 & 0.693 & 82 & 0.387 & 0.019 \\
\hline Oslo & 47,340 & 29,695 & $62.70 \%$ & 133 & 601 & $353.30 \%$ & 17,645 & 35,183 & 0.743 & 70 & 0.396 & 0.022 \\
\hline
\end{tabular}




\begin{tabular}{|c|c|c|c|c|c|c|c|c|c|c|c|c|}
\hline Milano Malpensa & 36,894 & 16,050 & $43.50 \%$ & 229 & 551 & $141.00 \%$ & 20,844 & 34,559 & 0.937 & 78 & 0.424 & 0.008 \\
\hline Copenhagen & 43,467 & 27,055 & $62.20 \%$ & 207 & 787 & $279.80 \%$ & 16,412 & 33,863 & 0.779 & 91 & 0.424 & 0.025 \\
\hline Stockholm Arlanda & 41,818 & 23,159 & $55.40 \%$ & 174 & 742 & $326.70 \%$ & 18,659 & 33,762 & 0.807 & 78 & 0.407 & 0.028 \\
\hline Moscow SVO & 40,299 & 23,099 & $57.30 \%$ & 353 & 848 & $140.40 \%$ & 17,200 & 33,463 & 0.830 & 112 & 0.420 & 0.02 \\
\hline Stansted & 35,871 & 16,065 & $44.80 \%$ & 119 & 614 & $416.20 \%$ & 19,806 & 32,384 & 0.903 & 81 & 0.362 & 0.008 \\
\hline Geneva & 34,319 & 15,416 & $44.90 \%$ & 184 & 771 & $318.20 \%$ & 18,903 & 31,088 & 0.906 & 69 & 0.407 & 0.004 \\
\hline Dublin & 34,389 & 15,114 & $44.00 \%$ & 158 & 499 & $215.00 \%$ & 19,275 & 30,748 & 0.894 & 75 & 0.401 & 0.008 \\
\hline Munich & 63,479 & 53,656 & $84.50 \%$ & 210 & 625 & $197.70 \%$ & 9,823 & 29,321 & 0.462 & 134 & 0.454 & 0.024 \\
\hline Manchester & 31,747 & 16,972 & $53.50 \%$ & 199 & 583 & $192.50 \%$ & 14,775 & 25,980 & 0.818 & 86 & 0.408 & 0.011 \\
\hline Frankfurt & 69,499 & 60,412 & $86.90 \%$ & 363 & 616 & $69.50 \%$ & 9,087 & 23,761 & 0.342 & 177 & 0.495 & 0.081 \\
\hline Vienna & 35,217 & 29,197 & $82.90 \%$ & 210 & 840 & $300.60 \%$ & 6,020 & 21,766 & 0.618 & 94 & 0.418 & 0.007 \\
\hline Dusseldorf & 40,820 & 31,309 & $76.70 \%$ & 164 & 420 & $156.50 \%$ & 9,511 & 19,302 & 0.473 & 86 & 0.419 & 0.007 \\
\hline Zurich & 34,432 & 26,912 & $78.20 \%$ & 269 & 662 & $146.50 \%$ & 7,520 & 17,537 & 0.509 & 98 & 0.447 & 0.014 \\
\hline Brussels & 33,536 & 25,485 & $76.00 \%$ & 197 & 488 & $148.00 \%$ & 8,051 & 16,457 & 0.491 & 93 & 0.431 & 0.011 \\
\hline
\end{tabular}

Table 11. Simulation results: Monday closure; alliance passenger recovery; intra-EEA markets.

\begin{tabular}{|c|c|c|c|c|c|c|c|c|c|c|c|c|}
\hline \multirow{2}{*}{$\begin{array}{l}\text { Closed } \\
\text { Airport }\end{array}$} & \multicolumn{12}{|c|}{ Intra-EEA markets } \\
\hline & dpax & reloc & \%reloc & $\begin{array}{r}\text { avt0 } \\
\text { (min) }\end{array}$ & $\begin{array}{r}\text { avt1 } \\
\text { (min) }\end{array}$ & $\Delta a v t \%$ & non-reloc & $\begin{array}{r}\text { aggdel }^{\prime} \\
\text { (pax-days) }\end{array}$ & $\begin{array}{l}\text { l'/dpax } \\
\text { (days) }\end{array}$ & $D i$ & $\mathrm{Ci}$ & $B i$ \\
\hline Barcelona & 58,220 & 26,749 & $45.9 \%$ & 127 & 876 & $587.8 \%$ & 31,471 & 56,936 & 0.978 & 89 & 0.513 & 0.055 \\
\hline Gatwick & 50,351 & 20,759 & $41.2 \%$ & 119 & 357 & $199.4 \%$ & 29,592 & 45,204 & 0.898 & 82 & 0.500 & 0.045 \\
\hline Madrid & $\mathbf{5 7 , 0 8 5}$ & 35,395 & $62.0 \%$ & 146 & 743 & $410.0 \%$ & 21,690 & 44,559 & 0.781 & 84 & 0.493 & 0.030 \\
\hline Heathrow & 59,333 & 43,877 & $74.0 \%$ & 143 & 746 & $421.0 \%$ & 15,456 & 38,441 & 0.648 & 62 & 0.482 & 0.011 \\
\hline Amsterdam & 45,988 & 25,950 & $56.4 \%$ & 161 & 685 & $325.3 \%$ & 20,038 & 36,949 & 0.803 & 99 & 0.515 & 0.039 \\
\hline Stansted & 35,357 & 15,845 & $44.8 \%$ & 115 & 607 & $425.4 \%$ & 19,512 & 33,543 & 0.949 & 80 & 0.463 & 0.064 \\
\hline Rome Fiumicino & 42,482 & 27,818 & $65.5 \%$ & 130 & 773 & $493.8 \%$ & 14,664 & 32,652 & 0.769 & 73 & 0.486 & 0.025 \\
\hline Oslo & 44,455 & 28,110 & $63.2 \%$ & 105 & 581 & $455.3 \%$ & 16,345 & 32,159 & 0.723 & 63 & 0.475 & 0.087 \\
\hline Stockholm Arlanda & 37,390 & 20,604 & $55.1 \%$ & 125 & 710 & $467.8 \%$ & 16,786 & 31,079 & 0.831 & 67 & 0.465 & 0.104 \\
\hline Copenhagen & 37,531 & 23,269 & $62.0 \%$ & 139 & 767 & $451.8 \%$ & 14,262 & 29,858 & 0.796 & 72 & 0.507 & 0.058 \\
\hline Dublin & 31,656 & 13,811 & $43.6 \%$ & 114 & 478 & $317.2 \%$ & 17,845 & 28,798 & 0.910 & 65 & 0.479 & 0.025 \\
\hline Paris Orly & 44,972 & 28,796 & $64.0 \%$ & 119 & 417 & $248.8 \%$ & 16,176 & 27,931 & 0.621 & 63 & 0.441 & 0.067 \\
\hline Geneva & 28,670 & 12,246 & $42.7 \%$ & 124 & 787 & $534.5 \%$ & 16,424 & 27,825 & 0.971 & 51 & 0.488 & 0.014 \\
\hline Milano Malpensa & 27,932 & 10,954 & $39.2 \%$ & 128 & 545 & $325.1 \%$ & 16,978 & 27,798 & 0.995 & 51 & 0.470 & 0.009 \\
\hline Paris CDG & 47,663 & 35,019 & $73.5 \%$ & 162 & 575 & $254.0 \%$ & 12,644 & 27,017 & 0.567 & 89 & 0.496 & 0.031 \\
\hline Munich & 48,422 & 41,132 & $84.9 \%$ & 130 & 588 & $353.8 \%$ & 7,290 & 23,296 & 0.481 & 86 & 0.503 & 0.028 \\
\hline Manchester & 24,657 & 14,560 & $59.1 \%$ & 131 & 566 & $330.9 \%$ & 10,097 & 18,885 & 0.766 & 65 & 0.489 & 0.035 \\
\hline Vienna & 24,659 & 21,212 & $86.0 \%$ & 136 & 850 & $524.7 \%$ & 3,447 & 15,450 & 0.627 & 61 & 0.468 & 0.018 \\
\hline Dusseldorf & 33,240 & 26,091 & $78.5 \%$ & 114 & 386 & $239.2 \%$ & 7,149 & 14,363 & 0.432 & 64 & 0.474 & 0.014 \\
\hline Zurich & 24,579 & 18,929 & $77.0 \%$ & 147 & 626 & $327.2 \%$ & 5,650 & 13,921 & 0.566 & 59 & 0.478 & 0.009 \\
\hline Frankfurt & 39,798 & 35,556 & $89.3 \%$ & 171 & 434 & $153.8 \%$ & 4,242 & 12,374 & 0.311 & 84 & 0.495 & 0.023 \\
\hline Brussels & 25,995 & 21,005 & $80.8 \%$ & 139 & 451 & $225.0 \%$ & 4,990 & 11,388 & 0.438 & 63 & 0.478 & 0.010 \\
\hline Moscow Sheremetyevo & 38 & 12 & $31.6 \%$ & 474 & 967 & $103.9 \%$ & 26 & 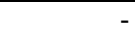 & - & 40 & - & - \\
\hline Istanbul Ataturk & 165 & 155 & $93.9 \%$ & 423 & 452 & $6.8 \%$ & 10 & - & - & 53 & - & - \\
\hline Moscow Domodedovo & 0 & 0 & - & - & - & - & 0 & - & - & 18 & - & - \\
\hline
\end{tabular}

Notes: dpax: disrupted passengers, reloc: relocated passengers; avt0: average baseline travel time (min) - relocated passengers; avt1: average relocated travel time (min); non-reloc: passengers not relocated; aggdel': aggregate delay for all passengers at 23:59 on Tuesday, Feb $5^{\text {th }}$ 2013; Di: degree centrality; Ci: closeness; Bi: Betweeness centrality.

Table 11 presents the results for the intra-EEA disrupted passengers. While there are many similarities with the overall results (intra-EEA is the largest market in the European airport network, see Table 1), the differences highlight the importance of using detailed demand data to assess airport criticality. On top of the geographical coverage of airline alliances and other restrictions that prevent relocation in particular routes, airports themselves play different roles in different markets. While Heathrow, Paris-CDG or Frankfurt devote the majority of their traffic to intercontinental routes, airports like Barcelona, Madrid, and Gatwick are mainly focused on intra-EEA traffic (Table 9). These three end up being the ones whose closure would cause the largest aggregate delays within the EEA internal markets. Among the rest, it is worth highlighting the difference between Heathrow and Paris-CDG, which, despite similar relocation rates, sharply differ in the quality of the alternative itineraries. Again, Frankfurt stands out as the least critical among the top European hubs, though its share of intra-EEA traffic is lower than all of the airports mentioned above. 
The first port of call when searching for the main drivers of airport criticality is network topology. As explained in Section 2, the existing literature has established a link between network damage and the topological properties of both the network and the individual airports. Table 12 shows the linear correlation and rank correlation coefficients between three of our demand-based indicators (increase in average travel time: $\Delta a v t \%$, aggregate delay: aggdel', and aggregate delay per passenger) and three supply-based topological measures (degree, closeness, and betweenness centrality). When all markets are considered, the topological indicators present a positive correlation to aggregate delays yet a negative correlation with the average increase in travel time and aggregate delay per passenger. The first result is capturing an "airport size" effect and is in line with the previous literature, which generally agrees that airports with the highest number of connections and lying in the highest proportion of shortest-paths between other airports would also generate the highest network damage when closed. In regards to the negative correlations, Hossain et al. (2013) notes that the most central an airport is, the easier is to find good surrogates to handle the disrupted traffic, thus potentially improving the quality of relocations. However, the correlation between centrality and network damage was still expected to be positive. This negative effect is not present in the EEA markets, where we find airports that serve as sole gateways to domestic/remote destinations (Oslo, Stockholm) and hence, they score high in both betweenness centrality and travel time increase as the remote regions become disconnected. Overall, the sign and magnitude of these correlations is much different from the supply-based measures by Hossain et al. (2013) in the range of 78\%-90\%. These results challenge the traditional views on the relationship between airport centrality and network damage from the perspective of passenger recovery, and a more comprehensive search for explanatory factors is warranted.

Table 12. Linear correlation and rank correlation coefficients: criticality vs. topological indicators

\begin{tabular}{|c|c|c|c|c|c|c|}
\hline & \multicolumn{3}{|c|}{ All markets } & \multicolumn{3}{|c|}{ Intra-EEA markets } \\
\hline & Degree & Closeness & Betweenness & Degree & Closeness & Betweenness \\
\hline \multicolumn{7}{|l|}{$\Delta a v t \%$} \\
\hline linear correlation & $-0.541 *$ & $-0.633^{*}$ & $-0.507 *$ & -0.131 & 0.073 & 0.259 \\
\hline rank correlation & $-0.616^{*}$ & $-0.588^{*}$ & $-0.479 *$ & -0.069 & -0.008 & 0.246 \\
\hline \multicolumn{7}{|l|}{$\overline{\text { aggdel }^{\prime}}$} \\
\hline linear correlation & $0.414^{*}$ & 0.234 & $0.399 *$ & $0.429 *$ & 0.356 & 0.393 \\
\hline rank correlation & 0.379 & 0.165 & $0.534 *$ & 0.419 & 0.269 & $0.529 *$ \\
\hline \multicolumn{7}{|l|}{ aggdel'/dpax } \\
\hline linear correlation & -0.388 & $-0.567 *$ & -0.304 & 0.039 & 0.067 & 0.276 \\
\hline rank correlation & -0.352 & $-0.530 *$ & -0.233 & -0.066 & 0.071 & 0.302 \\
\hline
\end{tabular}

\subsection{Drivers of airport criticality: originating vs. connecting traffic}

Understanding how passenger traffic is redistributed when a large airport closes can help identify the drivers of airport criticality. On the one hand, passengers starting or terminating their journey in a closed airport (i.e., od traffic) will be able to find an alternative itinerary if a local surrogate, that can be reached by ground transport, offers a compatible flight. Otherwise, od passengers will be "captive" in the closed airport until it reopens. Connecting traffic, on the other hand, is not dependent on local surrogates, but on finding a compatible connection elsewhere. Adapting the argument of structural network redundancy discussed in Zhang et al. (2015), the quality of the relocation in our case study is expected to reflect how the respective alliances overlap in their coverage of the affected markets.

In order to illustrate the impact of the above factors, Table 13 provides the top ten alternative airports for the ten largest closures in terms of disrupted passengers. The top alternative airports are the ones that experience the highest increase in passenger departures with respect to the baseline scenario. In addition, we also report the proportion of relocated passengers that have to wait for the affected airport to reopen. As expected, the top alternative airports in 
most cases match the dominant alliance of the closure airport (e.g., Heathrow and Madrid are both dominated by Oneworld - See Table 9). For Frankfurt and Paris-CDG, in what seems the most advantageous situation, the top alternative airports are alliance-matching surrogates (Dusseldorf and Orly, respectively), thus improving the chances of finding minimum-delay itineraries that can be completed via a road/rail transfer ${ }^{21}$. This can explain the exceptionally high quality of relocation for the Frankfurt closure, as only 55\% of disrupted passengers have to wait for the airport to reopen ${ }^{22}$. On the other end, the lack of apparent surrogates among the top alternates for Madrid or Barcelona is bound to translate into longer waiting times, though the impact is more acute in the latter due to the higher proportion of origin/destination (od) traffic over passenger connections (conn).

Table 13. Top alternative airports: Monday closure; alliance passenger recovery; all markets.

\begin{tabular}{|c|c|c|c|c|c|c|c|c|c|c|}
\hline \multirow[t]{2}{*}{ Closure } & \multicolumn{2}{|c|}{ Heathrow } & \multicolumn{2}{|c|}{ Paris-CDG } & \multicolumn{2}{|c|}{ Frankfurt } & \multicolumn{2}{|c|}{ Istanbul Ataturk } & \multicolumn{2}{|c|}{ Amsterdam } \\
\hline & reloc & non-reloc & reloc & non-reloc & reloc & non-reloc & reloc & non-reloc & reloc & non-reloc \\
\hline Total pax & 78,267 & 29,930 & 56,417 & 22,115 & 60,412 & 9,087 & 46,346 & 29,064 & 37,744 & 25,506 \\
\hline od pax & 64,573 & 23,488 & 41,294 & 18,070 & 35,756 & 5,691 & 31,442 & 19,631 & 25,128 & 20,318 \\
\hline Connecting pax & 13,694 & 6,442 & 15,123 & 4,045 & 24,656 & 3,396 & 14,904 & 9,433 & 12,616 & 5,188 \\
\hline \multirow{11}{*}{ 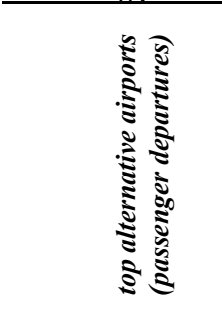 } & alt. & $\Delta$ pax & alt. & $\Delta$ pax & alt. & $\Delta$ pax & alt. & $\Delta$ pax & alt. & $\Delta$ pax \\
\hline & MAD & 6,097 & ORY & 9,246 & DUS & 9,970 & FRA & 8,123 & CDG & 8,870 \\
\hline & FRA & 5,956 & AMS & 6.881 & MUC & 8.462 & MUC & 6.834 & BRU & 6.590 \\
\hline & MUC & 5,071 & FCO & 4,941 & STR & 4.434 & ESB & 4,280 & LHR & 1,995 \\
\hline & LGW & 4,416 & SVO & 2,503 & $\mathrm{CGN}$ & 4,009 & VIE & 3,097 & SVO & 1,919 \\
\hline & $\mathrm{TXL}$ & 3,612 & FRA & 2,484 & VIE & 3.762 & DUS & 2.971 & ORY & 1,733 \\
\hline & $\mathrm{BCN}$ & 3.595 & BRU & 2.257 & IST & 3.156 & CAI & 2.605 & $\mathrm{FCO}$ & 1.681 \\
\hline & DUS & 3,194 & LIN & 2.166 & $\mathrm{ZRH}$ & 2,468 & BRU & 2.097 & LCY & 1,540 \\
\hline & HEL & 2.592 & LYS & 2,146 & $\mathrm{BRU}$ & 2,358 & SAW & 2,006 & MAD & 1,375 \\
\hline & $\mathrm{BRU}$ & 2.582 & TLS & 1.914 & HAM & 2,318 & $\mathrm{ZRH}$ & 1.984 & FRA & 1,249 \\
\hline & VIE & 2.523 & $\mathrm{NCE}$ & 1.843 & LHR & 2.313 & HAM & 1.963 & LIN & 1.228 \\
\hline \% After reopening & LHR & $83.4 \%$ & $\mathrm{CDG}$ & $72.9 \%$ & FRA & $55.6 \%$ & IST & $70.4 \%$ & AMS & $66.3 \%$ \\
\hline \multirow[t]{2}{*}{ Closure } & \multicolumn{2}{|c|}{ Madrid } & \multicolumn{2}{|c|}{ Munich } & \multicolumn{2}{|c|}{ Barcelona } & \multicolumn{2}{|c|}{ Gatwick } & \multicolumn{2}{|c|}{ Rome Fuimicino } \\
\hline & reloc & non-reloc & reloc & non-reloc & reloc & non-reloc & reloc & non-reloc & reloc & non-reloc \\
\hline Total pax & 42,442 & 25,944 & 53,656 & 9,823 & 29,954 & 34,871 & 23,329 & 36,600 & 36,396 & 18,621 \\
\hline od pax & 33,086 & 22,312 & 37,749 & 7,352 & 25,623 & 32,305 & 21,846 & 34,938 & 26,370 & 15,837 \\
\hline Connecting pax & 9,356 & 3,632 & 15,907 & 2,471 & 4,331 & 2,566 & 1,483 & 1,662 & 10,026 & 2,784 \\
\hline \multirow{11}{*}{ 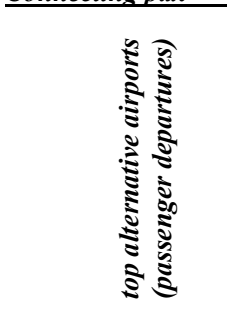 } & alt. & $\Delta$ pax & alt. & $\Delta$ pax & alt. & $\Delta \mathrm{pax}$ & alt. & $\Delta \mathrm{pax}$ & alt. & $\Delta$ pax \\
\hline & $\mathrm{BCN}$ & 8.529 & FRA & 9.202 & MAD & 8,819 & LHR & 4,464 & $\mathrm{CDG}$ & 7,213 \\
\hline & LHR & 6,240 & STR & 6,821 & LHR & 3,897 & STN & 2,064 & LIN & 5.944 \\
\hline & $\mathrm{CDG}$ & 2.685 & DUS & 5,633 & FRA & 1.963 & BRS & 1.883 & AMS & 2.756 \\
\hline & PMI & 1,971 & VIE & 4,506 & DUS & 1,614 & LTN & 1.609 & MXP & 2,447 \\
\hline & AMS & 1,909 & BRU & 3,480 & MUC & 1,595 & BHX & 1,316 & FRA & 1.811 \\
\hline & MUC & 1,855 & TXL & 3,272 & $\mathrm{CDG}$ & 1.560 & BFS & 978 & ORY & 1,799 \\
\hline & ORY & 1,813 & HAM & 3,196 & PMI & 1,523 & MAD & 883 & LHR & 1,689 \\
\hline & TXL & 1,574 & NUE & 3,129 & TXL & 1,444 & GVA & 766 & SVO & 1,347 \\
\hline & SVO & 1,538 & IST & 2,464 & BRU & 1,162 & $\mathrm{CDG}$ & 754 & MAD & 1,310 \\
\hline & DUS & 1,513 & CGN & 2,392 & ORY & 1,102 & AMS & 697 & CTA & 1,303 \\
\hline After reopening & MAD & $78.9 \%$ & MUC & $62.6 \%$ & $\mathrm{BCN}$ & $87.2 \%$ & LGW & $92.3 \%$ & $\mathrm{FCO}$ & $70.0 \%$ \\
\hline
\end{tabular}

Table 14 presents the shares of connecting and od traffic, alongside with two new indicators. First, we calculate the proportion of overlapping seat capacity (matching alliance and destination) offered by the airport's local surrogates (\% overlap surrogates). It ranges from $77.1 \%$ at Dusseldorf -whose passengers could potentially reach alliance-matching Frankfurt Airport within the set time limit of 130 minutes-, down to $0 \%$ for the relatively isolated Madrid and Rome airports. Second, we determine the proportion of connecting traffic for which the respective alliance networks offer at least one alternative connection point (\% overlap alliance). The values are strongly influenced by the distribution of traffic across alliance and non-alliance airlines. On one end, we find the $95.6 \%$ coverage of Zurich hub connections - mainly by Star Alliance -. On the other end, there is an $8.4 \%$ coverage for

\footnotetext{
${ }^{21}$ In the CDG case, having Orly as a surrogate reduces relocation times because a final ground transfer from Orly to CDG is not added since both airports serve the same city (Table 7).

${ }^{22}$ We ran the Frankfurt closure without the ground transport link to Dusseldorf in order to check the consistency of that estimate. The relocation rate would remain virtually the same $(86.7 \%)$, as well as the proportion of passengers after reopening $(55.8 \%)$. Only the increase in average relocation time would suffer (a $15 \%$ increase to $84.5 \%$ ) as Munich, Cologne, and Stuttgart airports absorbed the additional traffic.
} 
Dublin - dominated by Ryanair and Aer Lingus -, an airport with a very low share of connections. In order to account for these differences in traffic split, the two types of overlap can be combined to estimate the overall proportion of the airport's traffic that is not covered by any other alliance service either locally on in connection (\% non-overlap).

Table 14. Capacity overlap provided by airline alliances and surrogate airports

\begin{tabular}{|c|c|c|c|c|c|c|}
\hline Airport & \%conn & $\begin{array}{l}\text { overlap } \\
\text { alliance }\end{array}$ & $\% o d$ & $\begin{array}{l}\text { overlap } \\
\text { Irrogates }\end{array}$ & $\begin{array}{l}\text { \% non- } \\
\text { overlap }\end{array}$ & $\begin{array}{l}\text { Potential surrogates } \\
\text { (airports }<130 \text { min uncongested road/rail transfer) }\end{array}$ \\
\hline Heathrow & $12.8 \%$ & $43.0 \%$ & $87.2 \%$ & $13.1 \%$ & $83.1 \%$ & BHX BOH BRS LCY LGW LTN SEN SOU STN \\
\hline Barcelona & $3.6 \%$ & $82.0 \%$ & $96.4 \%$ & $1.8 \%$ & $95.3 \%$ & GRO ILD REU \\
\hline Istanbul & $28.0 \%$ & $51.1 \%$ & $72.0 \%$ & $5.4 \%$ & $81.8 \%$ & SAW TEQ \\
\hline Gatwick & $2.7 \%$ & $39.4 \%$ & $97.3 \%$ & $39.2 \%$ & $60.8 \%$ & BOH LCY LHR LTN MSF OXF SEN SOU STN \\
\hline Madrid & $13.8 \%$ & $51.7 \%$ & $86.2 \%$ & $0.0 \%$ & $92.9 \%$ & SLM VLL \\
\hline Amsterdam & $19.9 \%$ & $59.9 \%$ & $80.1 \%$ & $20.2 \%$ & $71.9 \%$ & BRU EIN GRQ MST NRN RTM \\
\hline Moscow Domodedovo & $10.0 \%$ & $12.1 \%$ & $90.0 \%$ & $6.9 \%$ & $92.6 \%$ & BKA SVO VKO \\
\hline Paris CDG & $17.2 \%$ & $65.5 \%$ & $82.8 \%$ & $10.7 \%$ & $79.9 \%$ & BVA DOL LEH LIL LTQ ORY XCR \\
\hline Rome Fuimicino & $15.4 \%$ & $55.6 \%$ & $84.6 \%$ & $0.0 \%$ & $91.4 \%$ & CIA \\
\hline Paris Orly & $3.6 \%$ & $64.4 \%$ & $96.4 \%$ & $20.9 \%$ & $77.5 \%$ & BVA CDG DOL LEH TUF XCR \\
\hline Oslo & $12.4 \%$ & $46.9 \%$ & $87.6 \%$ & $2.9 \%$ & $91.6 \%$ & RYG TRF \\
\hline Milano Malpensa & $1.3 \%$ & $82.6 \%$ & $98.7 \%$ & $20.0 \%$ & $79.2 \%$ & BGY GOA LYN LUG PMF TRN VRN \\
\hline Copenhagen & $15.3 \%$ & $70.8 \%$ & $84.7 \%$ & $5.1 \%$ & $84.8 \%$ & AGH HAD KID MMX RKE \\
\hline Stockholm Arlanda & $9.2 \%$ & $32.8 \%$ & $90.8 \%$ & $1.2 \%$ & $95.9 \%$ & BMA NRK NYO VST \\
\hline Moscow Sheremetyevo & $20.9 \%$ & $42.7 \%$ & $79.1 \%$ & $3.5 \%$ & $88.3 \%$ & BKA DME VKO \\
\hline Stansted & $0.1 \%$ & $29.4 \%$ & $99.9 \%$ & $35.7 \%$ & $64.3 \%$ & BHX EMA LCY LGW LHR LTN NWI OXF SEN \\
\hline Geneva & $1.1 \%$ & $88.1 \%$ & $98.9 \%$ & $26.5 \%$ & $72.8 \%$ & BRN DLE LYS NCY \\
\hline Dublin & $3.1 \%$ & $8.4 \%$ & $96.9 \%$ & $16.5 \%$ & $83.7 \%$ & BFS BHD WAT \\
\hline Munich & $23.0 \%$ & $85.2 \%$ & $77.0 \%$ & $26.9 \%$ & $59.7 \%$ & AGB PDH FMM INN NUE STR SZG \\
\hline Manchester & $2.2 \%$ & $55.1 \%$ & $97.8 \%$ & $44.1 \%$ & $55.7 \%$ & BHX BLK DSA EMA GLO HUY LBA LPL VLY \\
\hline Frankfurt & $31.6 \%$ & $73.0 \%$ & $68.4 \%$ & $38.6 \%$ & $50.5 \%$ & CGN DUS FKB HHN NUE SCN STR \\
\hline Vienna & $21.3 \%$ & $84.1 \%$ & $78.7 \%$ & $2.9 \%$ & $79.8 \%$ & BRQ BTS GRZ \\
\hline Dusseldorf & $6.8 \%$ & $87.7 \%$ & $93.2 \%$ & $77.1 \%$ & $22.2 \%$ & BRU CGN CRL DTM EIN FMO FRA MST NRN PAD \\
\hline Zurich & $18.3 \%$ & $95.6 \%$ & $81.7 \%$ & $29.4 \%$ & $58.5 \%$ & ACH BRN BSL FDH FMM MLH STR SXB \\
\hline Brussels & $7.7 \%$ & $71.8 \%$ & $92.3 \%$ & $66.0 \%$ & $33.5 \%$ & AMS CGN CRL DUS EIN LIL LUX MST NRN OST RTM \\
\hline
\end{tabular}

Similarly to the previous section, Table 15 presents the linear and rank correlation coefficients between our measures of airport criticality, the alliance non-overlap, the share of $o d$ traffic, and the market shares of alliance and non-alliance airlines. Results confirm the intuition that the alliance non-overlap presents a positive correlation to airport criticality, a positive and statistically significant relationship also exists between the share of od traffic and the aggregate delay per passenger. Among the market shares, the proportion of nonalliance traffic is the strongest correlate to aggregate delay per passenger. Clearly, nonalliance airlines will have a harder time in finding alternative itineraries for their disrupted passengers exclusively through their own flight networks. On the contrary, there is a negative correlation between delays per passenger and the market share of Star Alliance. While it is beyond the scope of this paper to establish causal relationships between alliance market shares and airport criticality, these correlations are in line with the results from Lordan et al. (2015) which point at Star Alliance as the most resilient of the three major alliances. ${ }^{23}$

Table 15. Linear correlation and rank correlation: criticality vs. traffic and network overlap indicators

\begin{tabular}{|c|c|c|c|c|c|c|}
\hline & \multicolumn{6}{|c|}{ All markets } \\
\hline & \%non-overlap & $\% o d$ & \%oneworld & \%staralliance & \%skyteam & \%non-alliance \\
\hline \multicolumn{7}{|l|}{$\overline{\Delta a v t \%}$} \\
\hline linear correlation & 0.368 & 0.382 & -0.043 & -0.059 & -0.238 & 0.324 \\
\hline rank correlation & 0.345 & 0.321 & -0.070 & -0.047 & -0.186 & 0.302 \\
\hline \multicolumn{7}{|l|}{$\overline{\text { aggdel }^{\prime}}$} \\
\hline linear correlation & $0.575^{*}$ & 0.019 & $0.457^{*}$ & $-0.444 *$ & 0.140 & 0.063 \\
\hline rank correlation & $0.599 *$ & -0.003 & 0.199 & -0.374 & 0.078 & 0.219 \\
\hline \multicolumn{7}{|l|}{$\overline{\text { aggdel'/dpax }}$} \\
\hline linear correlation & $0.580 *$ & $0.580 *$ & 0.007 & $-0.616^{*}$ & -0.007 & $0.668 *$ \\
\hline
\end{tabular}

${ }^{23}$ Indeed, a quick inspection of the MIDT dataset reveals that Star Alliance network offers an average of 1.81 routings per origin/destination market. This is followed by Skyteam with 1.51 and finally Oneworld with 1.45. The intuition is that a higher network redundancy makes passenger recovery easier in case of airport failure. 
In relation to the topological indicators, it is worth noting that neither degree nor betweenness centrality have been defined to capture the existence of local surrogates or the degree of alliance coverage. As a result, there is no statistically significant correlation between degree, betweenness, or closeness centrality and any of the capacity overlap indicators. This is not to say that our variables are the best predictors, but we argue that the positive correlations found, within the exploratory nature of this section, are grounds to support further research in this area. A graphical representation of how the relationship between these variables could be interpreted is shown in Figure 1.

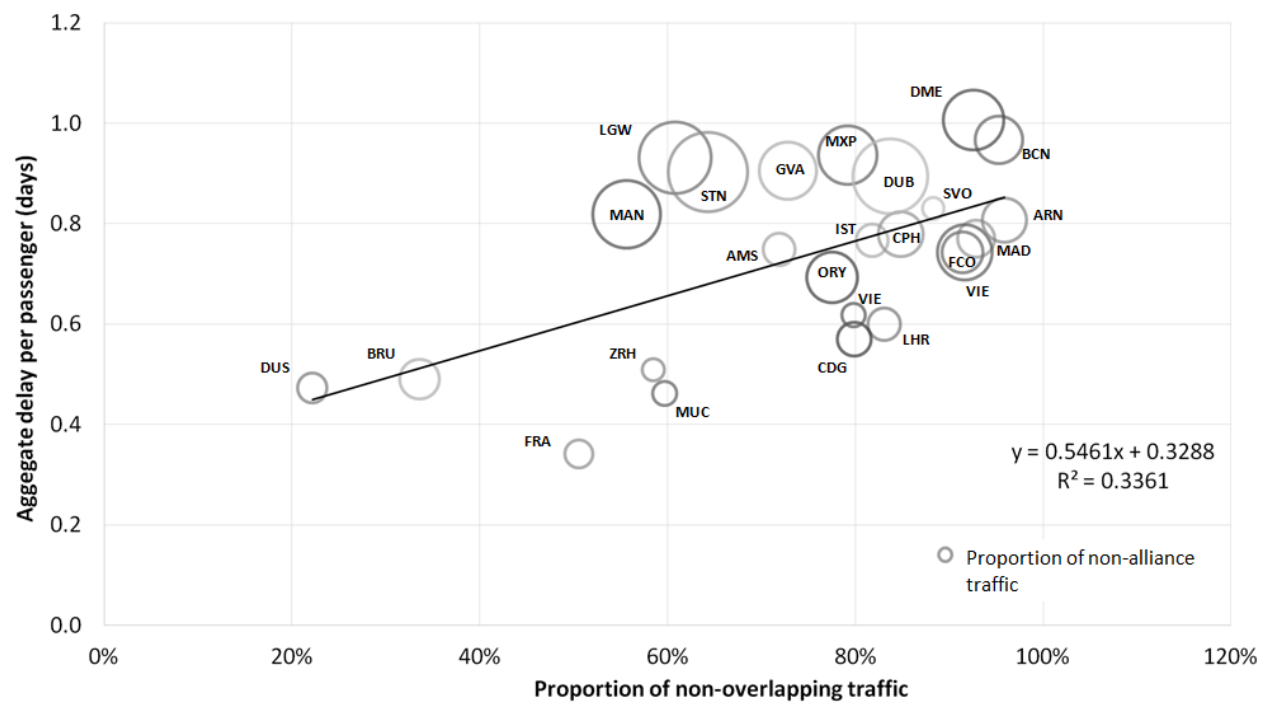

Figure 1. Aggregate delays per passenger vs proportions of non-overlapping and non-alliance traffic

In general, for the same level of non-overlapping traffic, a higher share of alliance traffic tends to reduce delays per passenger. Dual hub operations by major carriers can benefit relocation further by providing mutual hub alternatives for connecting markets. The prime examples of that are Frankfurt and Munich within Lufthansa's network (Star Alliance). There is also the coupling of Paris-CDG and Amsterdam within the network of Air France-KLM (Sky Team), though the chosen factors do not yet provide any explanation for the substantial difference in average delays between both airports. Low-cost and other non-alliance dominated airports, on the other hand, are among the most critical in terms of delays per passenger, regardless of the amount of traffic overlap provided by the local surrogates. In particular, it is worth mentioning the case of London Gatwick, which achieves the poorest relocation rate in the sample despite its passengers having access to many surrogate airports in South East England with low-cost capacity on offer.

We now explore the impact of the model restrictions in order to determine the limitations of the previous factors in explaining airport criticality. One of the most important of these restrictions is alliance recovery, implemented via the definition of a multi-layered network where relocation across layers is not possible. In order to quantify the negative impact of that restriction (as predicted by Cardillo et al., 2013), Table 16 provides a summary of the simulation results for the unrestricted recovery scenario. When all markets are considered, results show that inter-alliance cooperation can potentially increase relocation rates from $1.7 \%$ (Barcelona) up to $31.2 \%$ (Moscow-DME), with an average of $15.5 \%$. This leads to a reduction in aggregate delays between $1.2 \%$ (Barcelona) up to $45.2 \%$ (Frankfurt), with an average of $26.8 \%$. Since the increase in relocation rates clearly exceeds the proportion of inter-alliance traffic in most cases (Table 9), it is clear that the benefits of alliance 
cooperation extend to intra-alliance traffic due to cross-alliance network overlap. Interestingly, this impact can be different even between alliance-matching airports, such as Amsterdam and Paris-CDG. Due to the geography of Sky Team's network, the passenger connections at Amsterdam would benefit more from cross-alliance relocation than those connecting in Paris during the sample day ${ }^{24}$. However, the main effect of removing the alliance restriction is that it gives Amsterdam's od passengers access to the Star Alliance frequencies at Brussels, which then becomes main alternate airport under that closure scenario (See Appendix B).

Table 16. Simulation results: Monday closure; unrestricted passenger recovery.

\begin{tabular}{|c|c|c|c|c|c|c|c|c|}
\hline \multirow{2}{*}{$\begin{array}{l}\text { Closed } \\
\text { Airport }\end{array}$} & \multicolumn{4}{|c|}{ all markets } & \multicolumn{4}{|c|}{ intra-EEA markets } \\
\hline & \%reloc & diff. & aggdel' & diff. & \%reloc & diff. & aggdel $^{\prime}$ & diff. \\
\hline Barcelona & $47.9 \%$ & $1.7 \%$ & 61,965 & $-1.2 \%$ & $46.6 \%$ & $0.7 \%$ & $\mathbf{5 7 , 0 7 8}$ & $0.2 \%$ \\
\hline Madrid & $75.3 \%$ & $13.3 \%$ & 46,035 & $-12.6 \%$ & $73.4 \%$ & $11.4 \%$ & 41,385 & $-7.1 \%$ \\
\hline Heathrow & $83.6 \%$ & $11.3 \%$ & 41,214 & $-36.4 \%$ & $82.1 \%$ & $8.2 \%$ & 27,572 & $-28.3 \%$ \\
\hline Istanbul & $82.8 \%$ & $21.3 \%$ & 38,365 & $-33.7 \%$ & $98.8 \%$ & $4.8 \%$ & -1 & $-104.3 \%$ \\
\hline Gatwick & $62.7 \%$ & $23.8 \%$ & 37,217 & $-33.3 \%$ & $65.2 \%$ & $23.9 \%$ & 29,531 & $-34.7 \%$ \\
\hline Fiumicino & $83.3 \%$ & $17.2 \%$ & 32,696 & $-20.0 \%$ & $82.3 \%$ & $16.8 \%$ & 27,868 & $-14.7 \%$ \\
\hline Amsterdam & $81.0 \%$ & $21.3 \%$ & 29,878 & $-36.9 \%$ & $78.5 \%$ & $22.1 \%$ & 25,378 & $-31.3 \%$ \\
\hline Oslo & $74.7 \%$ & $12.0 \%$ & 29,019 & $-16.0 \%$ & $75.2 \%$ & $11.9 \%$ & 27,238 & $-17.6 \%$ \\
\hline Stockholm Arlanda & $69.4 \%$ & $14.0 \%$ & 28,875 & $-21.0 \%$ & $69.3 \%$ & $14.2 \%$ & 26,276 & $-20.7 \%$ \\
\hline Paris CDG & $85.2 \%$ & $13.3 \%$ & 28,731 & $-35.8 \%$ & $84.3 \%$ & $10.8 \%$ & 20,707 & $-23.4 \%$ \\
\hline Copenhagen & $73.5 \%$ & $11.3 \%$ & 28,721 & $-15.2 \%$ & $73.4 \%$ & $11.4 \%$ & 25,837 & $-13.5 \%$ \\
\hline Geneva & $67.1 \%$ & $22.1 \%$ & 28,299 & $-15.0 \%$ & $68.6 \%$ & $25.9 \%$ & 24,169 & $-14.0 \%$ \\
\hline Paris Orly & $72.6 \%$ & $13.9 \%$ & 28,113 & $-26.9 \%$ & $73.8 \%$ & $9.8 \%$ & 21,906 & $-21.6 \%$ \\
\hline Moscow Domodedovo & $70.7 \%$ & $31.2 \%$ & 27,919 & $-40.5 \%$ & - & - & 0 & - \\
\hline Dublin & $71.9 \%$ & $28.0 \%$ & 25,574 & $-19.2 \%$ & $72.4 \%$ & $28.8 \%$ & 24,746 & $-10.3 \%$ \\
\hline Stansted & $62.1 \%$ & $17.3 \%$ & 23,690 & $-29.3 \%$ & $62.0 \%$ & $17.2 \%$ & 22,969 & $-27.3 \%$ \\
\hline Munich & $93.3 \%$ & $8.8 \%$ & 22,243 & $-24.1 \%$ & $93.4 \%$ & $8.5 \%$ & 18,746 & $-19.5 \%$ \\
\hline Milano Malpensa & $67.2 \%$ & $23.7 \%$ & 19,940 & $-40.8 \%$ & $68.0 \%$ & $28.8 \%$ & 15,413 & $-45.2 \%$ \\
\hline Moscow Sheremetyevo & $80.0 \%$ & $22.7 \%$ & 19,631 & $-41.3 \%$ & $100.0 \%$ & $68.4 \%$ & 0 & $-100.0 \%$ \\
\hline Manchester & $71.8 \%$ & $18.4 \%$ & 18,477 & $-24.8 \%$ & $74.2 \%$ & $15.2 \%$ & 15,379 & $-13.0 \%$ \\
\hline Vienna & $93.9 \%$ & $11.0 \%$ & 16,949 & $-20.5 \%$ & $93.0 \%$ & $7.0 \%$ & 13,799 & $-8.5 \%$ \\
\hline Dusseldorf & $79.6 \%$ & $2.9 \%$ & 15,291 & $-16.9 \%$ & $80.5 \%$ & $2.0 \%$ & 12,203 & $-16.5 \%$ \\
\hline Frankfurt & $95.4 \%$ & $8.5 \%$ & 13,011 & $-45.2 \%$ & $95.9 \%$ & $6.6 \%$ & 8,241 & $-33.4 \%$ \\
\hline Brussels & $83.6 \%$ & $7.6 \%$ & 11,832 & $-24.4 \%$ & $85.9 \%$ & $5.1 \%$ & 8,559 & $-23.1 \%$ \\
\hline Zurich & $89.6 \%$ & $11.4 \%$ & 10,912 & $-37.8 \%$ & $88.9 \%$ & $11.9 \%$ & 9,133 & $-34.4 \%$ \\
\hline
\end{tabular}

Notes: diff indicates the difference with respect to the restricted scenarios from Tables 10 and 11.

Low-cost dominated airports like Gatwick, Stansted, and Dublin particularly benefit from the relocation opportunities brought by the alliances' flight networks, but in the first two cases, the unrestricted relocation rates remain below $70 \%$. The case of Barcelona is also noteworthy, since its performance barely changes with respect to the alliance recovery scenario. What keeps passengers from being relocated is seat capacity. If we run the original model with unlimited seat capacity (Appendix C), relocation rates rise above $90 \%$ in 22 out of the 25 closures, with individual improvements that range from $10 \%$ to $45 \%$. Therefore, the final methodological implication of this section is that ignoring seat capacity in the analysis of network vulnerability and airport criticality, as it is common in previous studies, will introduce a major distortion in the results.

Finally, the robustness of these results is discussed by changing the temporal scope of the simulations. All the rankings of airport criticality presented above refer to Monday closures. The results from the Friday simulation (shown in Appendix D) lead to slightly different rankings, but are fully consistent with all the conclusions in this section. More relevant is the expected variability in traffic across the year. Airports that experience strong seasonality will become more critical to the European network in the summer period. In order to illustrate

\footnotetext{
${ }^{24}$ The MIDT reveals that $26.2 \%$ of Sky Team's connecting passengers at Amsterdam could only be relocated in other alliances, while the same indicator for Paris is $21 \%$.
} 
that, Appendix E shows the results for a new simulation ${ }^{25}$ carried out using data from August 2013. We find that relocation rates are generally much lower in August than in February, which we attribute to the same factors discussed in the paper: increased $o d$ traffic in summer, increased non-alliance traffic (from $43.2 \%$ in February to $48.5 \%$ in August), and reduction in spare capacity (load factor in intra-European flights increases from $67.2 \%$ in February to $74.6 \%$ in August). A particularly interesting case is Palma de Mallorca (PMI) airport, which stands out as one of the most critical airports in August, despite not appearing in the February ranking. PMI airport shows the lowest relocation rate in the sample $(29.9 \%)$, which, besides of the above factors, can be attributed to the lack of road/rail surrogates for an island airport which may impose additional constraints to passenger relocation in the event of a closure.

\subsection{Policy and management implications}

From a policy perspective, the proposed method provides useful reference values for the development of strategies aimed at improving the resilience of the European transport network. The identification of critical airports for particular origin and destination markets can help directing investment to achieve high-level strategic objectives. One of these objectives is to ensure robust gate-to-gate travel times within the EEA. From the point of view of air transport, the intra-EEA is mainly a point-to-point market (approx. 10\% connecting traffic). Thus, resilience rests mainly on the ability of airlines to find local surrogate airports - the issues of accessibility and intermodality take center stage here-, as well as the available capacity of the affected airports to absorb the increased traffic after reopening. Unsurprisingly, the most critical airports in intra-EEA markets are: a) geographically isolated (e.g., Madrid), which prevents them to have local surrogates that can be reached by ground transport; b) located in airport systems in which the local surrogate has a low level of network overlapping with the closed airport or there is a high proportion of low-cost traffic (e.g., Barcelona); or c) part of an airport system in which the main surrogate is severely congested (e.g., London Gatwick).

Another high-level objective could be to reinforce the air transport links with emerging economies. With enough data, the proposed method can help determine how important foreign airports and airlines are to the worldwide connectivity of the EEA. In relation to that, the fact that Istanbul Ataturk is one of the most critical airports for the transportation of air passengers in the European continent, as well as the key player in facilitating air transport between EEA and non-EEA European countries is indeed relevant.

From an airport management and tactical perspective, quantifying the impact on passengers during airport closures can be used to justify pre-emptive investments in facilities, equipment, personnel, and intermodal connectivity, as well as emergency planning and the enactment of additional policies to guarantee the resilience of the network. One may argue that these results should be combined with models of climate risk in order to identify the places where there is a coincidence of bad weather conditions and high airport criticality. London airports could be used as example. After the extended closure of London Heathrow airport due to snow in December 2010, a resilience enquiry determined that additional investments in "an enhanced snow plan" were needed (Heathrow Airport, 2010). As a result, the airport operator invested $£ 36$ million in related staff and equipment (BBC, 2013) and have been investing more in resilience ever since.

Climate risk notwithstanding, airport criticality is affected by other factors. For example, the extreme criticality of Barcelona airport in this case study is a close reminder of the effects of the so-called "wildcat strike" by ground handling workers in late July 2006 (19 months

\footnotetext{
${ }^{25}$ Full details on the August simulation are available from the authors upon request.
} 
before the high-speed rail line with Madrid was inaugurated). The industrial action culminated with a runway incursion that paralyzed airport operations for 11 hours, affecting approximately 100,000 passengers (El País, 2006). The airport took four days to recover while the disrupted passengers camped across the entire terminal concourse in the absence of alternative means of transportation. Iberia, the dominant airline at the time, brought 100 staff members from other airports and provided additional seat capacity in critical routes. A similar situation occurred in late 2010, amidst a nationwide strike of Air Traffic Controllers (ATC), the national railway operator increased capacity in 4,800 seats on the high-speed train between Barcelona and Madrid (this would represent approximately 3.6\% of the disrupted passengers in our case study). Normality was recovered after five days (El País, 2010). By combining these past experiences with our estimates of airport criticality, and the prospects of an ongoing conflict with the ATC unions in Spain, a clear policy recommendation is the enactment of regulatory measures to ensure the continuous provision of ATC at least in the country's main airports.

From the perspective of airline operations and network development, results provide estimates of how demand would be geographically redistributed under a minimum-delay criterion, as well as the points in which adding capacity would help speeding up the return to normal after the shock. They also highlight the importance of inter-alliance cooperation, which could become a required procedure in emergency situations. In addition, the model provides a framework to quantify the benefits for airlines (and their main hubs) to either join an alliance or support the integration of other carriers. To illustrate this point, we ran the Monday simulation for the Heathrow closure adding Qatar Airways' seat capacity to the Oneworld network ${ }^{26}$ (the Middle Eastern airline joined the alliance in October 2013). The relocation rate at Heathrow would increase $2.3 \%$ and Doha airport would experience the highest increase in relocated traffic from Heathrow in non-EEA markets $(11.7 \%$ of the disrupted non-EEA passengers). This indicates that Qatar Airways is able to provide minimum-delay alternative itineraries in those routes against other options for passenger recovery within the alliance network. This type of evidence could also be valuable within the current debate about the increasingly dominant role of Middle Eastern airlines and airports in worldwide international markets and their relationships with other network carriers both in Europe and the US.

\section{SUMMARY, LIMITATIONS, AND FUTURE RESEARCH}

This paper undertakes an exploratory analysis of the vulnerability of the European air transport network to major airport closures from the perspective of the delays imposed to disrupted airline passengers. Using an MIDT dataset on passenger itineraries flown during February 2013, full-day individual closures of the 25 busiest European airports are simulated and disrupted passengers then relocated to minimum-delay itineraries within the respective alliances' networks where seat capacity is available.

From a methodological perspective, our results illustrate the added value of employing demand data and modelling passenger recovery for a true system-based assessment of the vulnerability of air transport networks. The traditional topological indicators of degree and betweenness centrality, used by previous air transport studies, are not able to capture important drivers of structural network redundancy that the broad literature on transport networks identifies as relevant as well. In our case study, these factors include both the capacity provided by local surrogate airports and the specific network overlap from the respective airline alliances, which are shown to have an impact on passenger relocation delays. As a consequence, the proportion of non-alliance traffic is a strong predictor of

\footnotetext{
${ }^{26}$ Full simulation results under that scenario are available from the authors upon request.
} 
aggregate delay per passenger. Airports dominated by non-alliance airlines (e.g. low-cost carriers) will be less successful in finding alternative itineraries for their disrupted passengers exclusively through their own flight networks. When alliance restrictions are removed, the benefits in terms of passenger recovery extend to intra-alliance traffic due to cross-alliance network overlap. Finally, it is worth noting the importance of accounting for seat capacity restrictions, which can prevent early recovery of up to $45 \%$ of disrupted passengers.

An additional contribution is the ability to disaggregate the impact according to geographical market. Our rankings point at Heathrow airport as the most critical in the European air transport network in terms of aggregated delays, while Barcelona would take that spot for the intra-EEA markets. The latter airport is affected by the lack of compatible surrogates and significant capacity constraints to handle the amount of disrupted traffic generated by a 24hour closure. Within the largest European hubs, Frankfurt stands out as the most resilient overall due to its relatively low share of non-alliance traffic, the good network coverage of connecting routes (supported by Lufthansa's dual-hub strategy), and the availability of alliance-matching surrogate airports.

From a policy and managerial perspective, the proposed method provides useful reference values for the development of strategies aimed at improving the resilience of the European transport network. The identification of critical airports for particular origin and destination markets can help directing investment to suit high-level strategic objectives, such as ensuring robust gate-to-gate travel times within the European Union, or reinforcing the air transport links with emerging economies. The quantification of the short-term passenger delays resulting from airport closures (especially those in geographical isolation), can be used to support additional investments in equipment, personnel, and intermodal connectivity to mitigate the impact on the system. From the perspective of airline operations and network development, results highlight the importance of inter-alliance cooperation and provide a framework to quantify the benefits for airlines (and their main hubs) to either join an alliance or support the integration of other carriers.

Our results, however, are conditioned to the limited post-reopening search period ( 24 hours) and the $130 \mathrm{~min}$ uncongested road/rail transfer. The first constraint is imposed by the available computational capacity. Expanding the search period will increase the relocation rate but at the same time also increase the aggregate delays. Taking into account that i) most closure scenarios see the majority of their passengers relocated within the set time, and ii) poorly performing airports face important capacity constraints, no significant variation of the airport rankings is expected. Increasing the time limit for surrogate airports will require modifying the model to allow for ground transport modes (such as high-speed rail) to substitute air travel in short-haul trips, thus expanding the scope of this research to analyse the resilience of the integrated European transport network. This could lead to interesting estimates, e.g. what is the contribution of Eurostar trains or the Madrid/Barcelona high-speed rail line to passenger recovery when any of the relevant airports fails?

Expanding the temporal scope of analysis to capture additional sources of airport criticality is a straightforward extension of our paper, but the proposed model has many other applications. In its current form, it can also be used to simulate extended airport closures of single airports, city-wide multi-airport systems, or even nationwide networks. One aspect that the current approach ignores (simply because of computational limitations) is the possibility of a high correlation between multiple airport closures in the same geographical region due to, for example, weather conditions. In that context, it is not realistic to assume that ground transfer links between airports in the same affected area will remain a valid alternative to stranded passengers, thus also creating more delays and relocation costs. With enough depth 
of computation, determining the number of days it takes the system to fully absorb the shock is an alternative way to approach the analysis of network vulnerability and airport criticality. Additional applications include airline failures at their main bases or even entire shutdowns due to e.g. industrial actions. Another objective is to model airspace closures linked to weather conditions or armed conflicts. The geographical scope of analysis can also be expanded to include the worldwide airport network, with particular attention to the Middle East hubs and their increasingly dominant role in connecting markets.

We conclude by proposing three main avenues for further research in order to overcome the many limitations of our current methodology:

i) Introduce a set of criteria to prioritize different options of passenger recovery across layers (e.g. airline, alliance, interline partners, other airlines) in order to model the passenger rescheduling process in a more realistic fashion. This can be achieved by incorporating the published IROPS (Irregular Operations) guidelines for the major carriers into the rescheduling algorithm.

ii) Introducing aircraft and crew recovery decisions by the affected airlines. Due to the European-wide scale of our case study, a sequential approach would reduce the complexity of the model. Given a particular airport closure, airlines would first relocate their crews and aircraft following an objective of cost minimization (Barnhart, 2009). The updated flight schedules could then be used in the passenger recovery stage as described in this paper. This model would have to consider aspects that our simplified simulation ignores, such as the constraints imposed by crew work rules, maintenance schedules, airport capacity and airside congestion, the impact of flight diversions, and the propagation of delays across the flight network to other airports. In addition, the use of airline costs as objective function in this optimization process will lead to useful estimates for airline managers and policymakers.

iii) Combining flight and rail schedules in the distance matrix and introducing a passenger choice model. Potentiating intermodal connections between air and rail transport modes in order to reduce gate-to-gate travel times and improve the resilience of the European transportation network is one of the high-level objectives of the European Commission for 2050 (EC, 2014a). In that regard, the introduction of rail schedules would allow for a more realistic picture of the travel options available to each disrupted passenger. The potential of these new travel alternatives will only be fully exploited with an econometric model of passenger choice. This would require the collecting information on variables such as: air and rail fares, competition, access and travel times, and booking classes. A Multinomial Logit model of travel itinerary selection has been employed by many authors in this context and could be applied to that end (See Grosche, 2009).

\section{ACKNOWLEDGEMENTS}

This research project has been partly funded by the University of Edinburgh Business School through the Early Venture Fund program. The authors would also like to thank the support of the Business School IT department.

\section{REFERENCES}

Abdelghany, K., Abdelghany, A., and Ekollu, G., 2008. An integrated decision support tool for airlines schedule recovery during irregular operations. European Journal of Operational Research 185 (2), 825-848.

Albert, R., Jeong, H., and Barabási, A., 2000. Error and attack tolerance of complex networks. Nature 406 (6794), 378-382.

Allan, S., Beesley, A., Evans, E., Gaddy, S., 2001. Analysis of delay causality at Newark international airport, 4th USA/Europe Air Traffic Management R\&D Seminar, Santa Fe, USA.

ARG. 2013. Atmosphere's Global Travel Industry Executive Survey., Q3 2012.

http://www.iata.org/whatwedo/stb/Documents/future-airline-distribution-report.pdf 
Barnhart, C., 2009. Irregular Operations: Schedule Recovery and Robustness, in The Global Airline Industry (eds P. Belobaba, A. Odoni and C. Barnhart), John Wiley \& Sons, Ltd, Chichester, UK.

BBC, 2013. Heathrow Airport: Snow causes more flight delays. 20/01/2013

Berdica, K., 2002. An introduction to road vulnerability: what has been done, is done and should be done. Transport Policy 9, 117-127.

Berle, O., Asbjornslett, B., and Rice, J., 2011. Formal vulnerability assessment of a maritime transportation system. Reliability Engineering and System Safety 96, 696-705.

Bratu, S., and Barnhart, C., 2006. Flight operations recovery: New approaches considering passenger recovery. Journal of Scheduling 9 (3), 279-298.

Cacchiani, V., Huisman, D., Kidd, M., Kroon, L., Toth, P., Veelenturf, L., Wagenaar, J., 2014. An overview of recovery models and algorithms for real-time railway rescheduling. Transportation Research Part B 63, 15-37.

Cardillo, A., Zanin, M., Gómez-Gardeñez, J., Romance, M., Garcia del Amo, A., and Boccaletti, S., 2013. Modeling the multi-layer nature of the European Air Transport Network: Resilience and passengers rescheduling under random failures. Eur. Phys. J. Special Topics 215, 23-33.

Cats, O., Jenelius, E., 2015. Planning for the unexpected: the value of reserve capacity for public transport network robustness. Transportation Research Part A 81, 47-61.

Chen, A., Yang, H., Lo, H., Tang, W., 2002. Capacity reliability of a road network: an assessment methodology and numerical results. Transportation Research Part B 36, 225-252.

Chen, L., Miller-Hooks, E., 2012. Resilience: an indicator of recovery capability in intermodal freight transport. Transport Science 46, 109-123.

Chi, L.P., Cai, X., 2004. Structural changes caused by error and attack tolerance in US airport network. International Journal of Modern Physics B 18, 2394-2400.

De-Los-Santos, A., Laporte, G., Mesa, J., Perea, F., 2012. Evaluating passenger robustness in a rail transit network. Transportation Research Part C 20, 34-46.

Derrible, S., Kennedy, C., 2010. The complexity and robustness of metro networks. Physica A 389, 3678-3691.

DiPietro, G., Matthews, H., Hendrickson, C., 2014. Estimating economic and resilience consequences of potential navigation infrastructure failures: a case study of the Monongahela River. Transportation Research Part A 69, 142-164.

D'Este, G., and Taylor, M., 2003. Network vulnerability: an approach to reliability analysis at the level of national strategic transport networks. Proceedings of the 1st International Symposium on Transportation Network Reliability (INSTR), 23-44.

D'Lima, M., and Medda, F., 2015. A new measure of resilience: An application to the London Underground. Transportation Research Part A 81, 35-46.

Ducruet, C., Lee, S., and Ng, A., 2010. Centrality and vulnerability in liner shipping networks: revisiting the Northeast Asian port hierarchy. Maritime Policy and Management 37 (1), 17-36.

EC, 2014a. Horizon 2020 Work Programme 2014-2015 in the area of air transport. European Commission.

EC, 2014b. New State aid rules for a competitive aviation industry. Competition Policy Brief February 2014. European Commission.

El-Rashidy, R., Grant-Muller, S., 2014. An assessment method for highway network vulnerability. Journal of Transport Geography 34, 34-43.

El País, 2006. La huelga salvaje del personal de tierra de Iberia paraliza el aeropuerto de Barcelona. 29/07/2006

El País, 2010. Casi 5.000 vuelos anulados y 700.000 afectados en el puente más largo. 09/12/2010

Faturechi, R., Miller-Hooks, E., 2015. Measuring performance of transportation infrastructure systems in disaster: a comprehensive review. ASCE Journal of Infrastructure Systems 21(1).

Grosche, T., 2009. Computational Intelligence in Integrated Airline Scheduling. Studies in Computation Intelligence 173. Springer-Verlag Berlin Heidelberg.

Guida, M., and Maria, F., 2007. Topology of the Italian airport network: A scale-free small-world network with a fractal structure? Chaos, Solitons and Fractals 31 (3), 527-536.

Guimerà, R., Mossa, S., Turtschi, A. and Amaral, L. A. N., 2005. The worldwide air transportation network: Anomalous centrality, community structure, and cities' global roles. Proceedings of the National Academy of Sciences of the United States of America 102 (22), 7794-7799.

Heathrow Airport. 2010. Heathrow winter resilience enquiry report. March 2011.

Hossain, M., Alam, S. Rees, T., and Abbass, H. 2013. Australian Airport Network Robustness Analysis: A Complex Network Approach. Australasian Transport Research Forum 2013 Proceedings 2 - 4 October 2013, Brisbane, Australia

ICAO, 2013. Global Air Transport Outlook to 2030 and trends to 2040 (Circular 333). International Civil Aviation Organization. http://www.icao.int

Janic, M., 2005. Modeling the large scale disruptions of an airline network. Journal of Transportation Engineering, 131 (4), 249-260. 
Janic. M., 2015. Modeling the resilience, friability and costs of an air transport network affected by a large-scale disruptive event. Transportation Research Part A: Policy and Practice 71 (1), 1-16.

Jenelius, E., Petersen, T., Mattsson, L., 2006. Importance and exposure in road network vulnerability analysis. Transportation Research Part A 40, 537-560.

Jenelius, E., Mattsson, L., 2012. Road network vulnerability analysis of area-covering disruptions: a grid-based approach with case study. Transportation Research Part A 46, 746-760.

Kohl, N., Larsen, A., Larsen, J., Ross, A., and Tiourine, S., 2007. Airline disruption management-Perspectives, experiences and outlook. Journal of Air Transport Management 13 (3), 149-162.

Lettovsky, L., Johnson, E., and Nemhauser, G., 2000. Airline crew recovery. Transportation Science 34 (4), 337-348.

Li, Y., Kim, H., 2014. Assessing the survivability of the Beijing subway system. International Journal of Geospatial Environmental Research 1 (1). Article 3.

Lordan, O., Sallan, J., and Simo, P., 2014a. Study of the topology and robustness of airline route networks from the complex network approach: A survey and research agenda. Journal of Transport Geography 37, 112-120.

Lordan, O., Sallan, J.M., Simo, P., and Gonzalez-Prieto, D., 2014b. Robustness of the air transport network. Transportation Research Part E: Logistics and Transportation Review 68, 155-163.

Lordan, O., Sallan, J., Simo, P., and Gonzalez-Prieto, D., 2015. Robustness of airline alliance route networks. Communications in Nonlinear Science and Numerical Simulation 22, 587-595.

Mattsson, L. And Jenelius, E., 2015. Vulnerability and resilience of transport systems - A discussion of recent research. Transportation Research Part A 81, 16-34.

Maher, S., 2015. A novel passenger recovery approach for the integrated airline recovery problem. Computers and Operations Research 57, 123-137.

Mazzocchi, M., Hansstein, F., and Ragona, M., 2010. The 2010 Volcanic Ash Cloud and Its Financial Impact on the European Airline Industry. CESifo Forum No. 2: 92-100.

Petersen, J., Sölveling, G., Clarke, J., Johnson, E., and Shebalov, S., 2012. An optimization approach to airline integrated recovery. Transportation Science 46 (4), 482-500.

Reggiani, A., Nijkamp, P., and Cento, A., 2010. Connectivity and competition in airline networks. A study of Lufthansa's network. In: Vervest et al. (eds.). The network experience. Springer, Berlin.

Reggiani, A., Nijkamp, P., and Lanzi, D., 2015. Transport resilience and vulnerability: the role of connectivity. Transportation Research Part A 81, 4-15.

Rocha, L., 2009. Structural evolution of the Brazilian airport network. Journal of Statistical Mechanics P0420.

Rodríguez-Núñez, E., García-Palomares, J., 2014. Measuring the vulnerability of public transport networks. Journal of Transport Geography 35, 50-63.

Rose, A., 2007. Economic resilience to natural and man-made disasters: multidisciplinary origins and contextual dimensions. Environmental Hazards 7 (4), 383-398.

Schaefer, L., and Millner, D., 2001. Flight delay propagation analysis with the detailed policy assessment tool. Proceedings of the 2001 IEEE Systems, Man and Cybernetics Conference, Tucson, USA

Schavell, A., 2000. The effects of schedule disruptions on the economics of airline operations. 3rd USA/Europe Air Traffic Management R\&D Seminar, Napoli, Italy.

Suau-Sanchez, P., Voltes-Dorta, A., Rodríguez-Déniz, H., 2014. The role of London airports in providing connectivity for the UK: Regional dependence on foreign hubs. Journal of Transport Geography. DOI: dx.doi.org/10.1016/j.jtrangeo.2014.11.008

Suau-Sanchez, P., Voltes-Dorta, A., Rodríguez-Déniz, H., 2015. Regulatory Airport classification in the US: The role of international markets. Transport Policy 37, 157-166.

Thekdi, S., and Santos, J., 2015. Supply Chain Vulnerability Analysis Using Scenario-Based Input-Output Modeling: Application to Port Operations. Risk Analysis DOI: 10.1111/risa.12473.

Wang, J., Mo, H., Wang, F., and Jin, F., 2011. Exploring the network structure and nodal centrality of China's air transport network: A complex network approach. Journal of Transport Geography 19, 712-721.

Yan, S., and Lin, C., 1997. Airline scheduling for the temporary closure of airports. Transportation Science, 31 (1), $72-82$.

Zanin, M., 2015. Can we neglect the multi-layered structure of functional networks? Physica A: Statistical Mechanics and its Applications 430 (15), 184-192.

Zanin, M., Lillo, F., 2013. Modeling the air transport with complex networks: a short review. European Physical Journal Special Topics 215 (1), 5-21.

Zeng, X., Tang, X., and Jiang, K., 2011. Empirical study of Chinese airline network structure based on complex network theory. Journal of Transportation Systems Engineering and Information Technology 11(6), 175-181.

Zhang, X., Miller-Hooks, E., and Denny, K. 2015. Assessing the role of network topology in transportation network Resilience. Journal of Transport Geography 46, 35-45. 
Appendix A. Simulation results: Airport closure on Monday, February $4^{\text {th }} 2013$ between from 00:00 to 23:59 UTC; passenger recovery via alliance network.

\begin{tabular}{|c|c|c|c|c|c|c|c|c|c|c|c|c|c|c|c|c|c|c|c|c|c|c|c|c|}
\hline \multirow{2}{*}{$\begin{array}{l}\text { Closed } \\
\text { Airport }\end{array}$} & \multicolumn{12}{|c|}{ All markets } & \multicolumn{12}{|c|}{ intra-EEA markets } \\
\hline & dpax & conn & $\%$ conn & reloc & \%reloc & avto & avt1 & $\Delta a v t \%$ & aggdel & aggdel' alt. & $\Delta p a x$ & \%reloc & dpax & conn & \%conn & reloc & \%reloc & & & $\Delta \%$ & aggdel & aggdel' alt. & $\Delta p a x$ & \%reloc \\
\hline$\overline{\mathrm{LHR}}$ & 108,197 & 13,896 & $12.8 \%$ & 78,267 & $72.3 \%$ & 348 & 805 & $131.5 \%$ & 24,850 & 64,832 FRA & 6,160 & $7.9 \%$ & 59,333 & 3,604 & $6.1 \%$ & 43,877 & $74.0 \%$ & 143 & 746 & $421.0 \%$ & 18,360 & 38,441 FRA & 4,594 & $10.5 \%$ \\
\hline CDG & 78,532 & 13,472 & $17.2 \%$ & 56,417 & $71.8 \%$ & 322 & 687 & $113.2 \%$ & 14,299 & 44,758 ORY & 9,246 & $16.4 \%$ & 47,663 & 4,701 & $9.9 \%$ & 35,019 & $73.5 \%$ & 162 & 575 & $254.0 \%$ & 10,032 & 27,017 ORY & 6,791 & \\
\hline FRA & 69,499 & 21,971 & $31.6 \%$ & 60,412 & $86.9 \%$ & 363 & 616 & $69.5 \%$ & 10,600 & 23,761 DUS & 9,970 & $16.5 \%$ & 39,798 & 8,970 & $22.5 \%$ & 35,556 & $89.3 \%$ & 171 & 434 & $153.8 \%$ & 6,488 & 12,374 DUS & 7,155 & $20.1 \%$ \\
\hline IST & 75,410 & 21,130 & $28.0 \%$ & 46,346 & $61.5 \%$ & 300 & 807 & $168.5 \%$ & 16,292 & 57,843 FRA & 8,123 & $17.5 \%$ & 165 & 165 & $100.0 \%$ & 155 & $93.9 \%$ & 423 & 452 & $6.8 \%$ & 3 & 21 MUC & 74 & $47.7 \%$ \\
\hline AMS & 63,250 & 12,595 & $19.9 \%$ & 37,744 & $59.7 \%$ & 319 & 765 & $139.8 \%$ & 11,695 & $47,370 \mathrm{CDG}$ & 8,870 & $23.5 \%$ & 45,988 & 5,408 & $11.8 \%$ & 25,950 & $56.4 \%$ & 161 & 685 & $325.3 \%$ & 9,439 & $36,949 \mathrm{CDG}$ & 5,837 & $22.5 \%$ \\
\hline MU & 63,479 & 14,606 & $23.0 \%$ & 53,656 & $84.5 \%$ & 210 & 625 & $197.7 \%$ & 15,453 & 29,321 FRA & 9,202 & $17.1 \%$ & 48,422 & 8,721 & $18.0 \%$ & 41,132 & $84.9 \%$ & 130 & 588 & 353 & 13,096 & 23,296 FRA & 6,711 & $16.3 \%$ \\
\hline $\mathrm{FCO}$ & 55,017 & 8,474 & $15.4 \%$ & 36,396 & $66.2 \%$ & 231 & 815 & $252.9 \%$ & 14,768 & $40,864 \mathrm{CDG}$ & 7,213 & $19.8 \%$ & 42,482 & 4,692 & $11.0 \%$ & 27,818 & $65.5 \%$ & 130 & 773 & $493.8 \%$ & 12,419 & 32,652 LIN & 5,243 & $18.8 \%$ \\
\hline LGW & 59,929 & 1,611 & $2.7 \%$ & 23,329 & $38.9 \%$ & 162 & 385 & $137.8 \%$ & 3,615 & 55,821 LHR & 4,464 & $19.1 \%$ & 50,351 & 963 & $1.9 \%$ & 20,759 & $41.2 \%$ & 119 & 357 & $199.4 \%$ & 3,424 & 45,204 LHR & 3,641 & $17.5 \%$ \\
\hline $\mathrm{BCN}$ & 64,825 & 2,360 & $3.6 \%$ & 29,954 & $46.2 \%$ & 174 & 884 & $408.8 \%$ & 14,770 & 62,718 MAD & 8,819 & $29.4 \%$ & 58,220 & 1,957 & $3.4 \%$ & 26,749 & $45.9 \%$ & 127 & 876 & $587.8 \%$ & 13,903 & 56,936 MAD & 8,371 & $31.3 \%$ \\
\hline DME & 46,649 & 4,658 & $10.0 \%$ & 18,428 & $39.5 \%$ & 235 & 502 & $114.1 \%$ & 3,426 & $46,952 \mathrm{SVO}$ & 051 & $5.7 \%$ & 0 & 0 & & 0 & & & & & 0 & 0 & 0 & $0.0 \%$ \\
\hline SVO & 40,299 & 8,422 & $20.9 \%$ & 23,099 & $57.3 \%$ & 353 & 848 & $140.4 \%$ & 7,948 & $33,463 \mathrm{CDG}$ & 5,410 & $23.4 \%$ & 38 & 38 & $100.0 \%$ & 12 & $31.6 \%$ & 474 & 967 & $3.9 \%$ & 4 & us & 0 & $5.0 \%$ \\
\hline $\mathrm{CPH}$ & 43,467 & 6,672 & $15.3 \%$ & 27,055 & $62.2 \%$ & 207 & 787 & $279.8 \%$ & 10,889 & 33,863 FRA & 5,017 & $18.5 \%$ & 37,531 & 5,477 & $14.6 \%$ & 23,269 & $62.0 \%$ & 139 & 767 & $451.8 \%$ & 10,146 & 29,858 FRA & 4,582 & $19.7 \%$ \\
\hline ZRH & 34,432 & 6,287 & $18.3 \%$ & 26,912 & $78.2 \%$ & 269 & 662 & $146.5 \%$ & 7,354 & 17,537 STR & 5,524 & & 24,579 & 3,181 & $12.9 \%$ & 18,929 & $77.0 \%$ & 147 & 626 & $327.2 \%$ & 6,305 & $13,921 \mathrm{STR}$ & 4,445 & $23.5 \%$ \\
\hline A & 34,319 & 393 & $1.1 \%$ & 15,416 & $44.9 \%$ & 184 & 771 & $318.2 \%$ & 6,2 & 5 LYS & 4,41 & 28. & 28,670 & 256 & $0.9 \%$ & 12,246 & $42.7 \%$ & 124 & 78 & $534.5 \%$ & 5,636 & 28,544 LYS & 3,156 & $25.8 \%$ \\
\hline MXP & 36,894 & 463 & $1.3 \%$ & 16,050 & $43.5 \%$ & 229 & 551 & $141.0 \%$ & 3,596 & 34,382 LIN & 2,675 & $16.7 \%$ & 27,932 & 209 & $0.7 \%$ & 10,954 & $39.2 \%$ & 128 & 545 & $325.1 \%$ & 3,170 & 25,922 LIN & 1,626 & $14.8 \%$ \\
\hline STN & 35,871 & 47 & $0.1 \%$ & 16,065 & $44.8 \%$ & 119 & 614 & $416.2 \%$ & 5,527 & 33,786 BRS & 1,600 & $10.0 \%$ & 35,357 & 43 & $0.1 \%$ & 15,845 & $44.8 \%$ & 115 & 607 & $425.4 \%$ & 5,406 & 31,808 BRS & 1,600 & $10.1 \%$ \\
\hline DUB & 34 & 1,051 & $3.1 \%$ & 15,114 & $44.0 \%$ & 158 & 499 & 21 & 3,573 & $97 \mathrm{Ll}$ & 1,6 & 10.6 & 31, & 789 & $2.5 \%$ & 13 , & $43.6 \%$ & 11 & 478 & 317. & 3, & 8 LHR & 1, & $11.0 \%$ \\
\hline DL & 40,820 & 2,759 & $6.8 \%$ & 31,309 & $76.7 \%$ & 164 & 420 & $156.5 \%$ & 5,576 & 19,146 FRA & 7,907 & $25.3 \%$ & 33,240 & 2,001 & $6.0 \%$ & 26,091 & $78.5 \%$ & 114 & 38 & $239.2 \%$ & 4,931 & 14,771 FRA & 6,555 & $25.1 \%$ \\
\hline MAN & 31,747 & 701 & $2.2 \%$ & 16,972 & $53.5 \%$ & 199 & 583 & $192.5 \%$ & 4,525 & $25,325 \mathrm{BHX}$ & 3,379 & 199 & 24,657 & 481 & $2.0 \%$ & 14,560 & $59.1 \%$ & 131 & 56 & $330.9 \%$ & 4,393 & 35 BHX & 2,895 & $19.9 \%$ \\
\hline BRU & & 2,573 & $7.7 \%$ & 25,485 & & 197 & 488 & & 5,149 & $16,667 \mathrm{D}$ & 5,8 & & 25,995 & 1,800 & $6.9 \%$ & 21,005 & $80.8 \%$ & 139 & 45 & $225.0 \%$ & 4,557 & 11,403 DUS & 5,013 & $23.9 \%$ \\
\hline VIE & 35,217 & 7,509 & $21.3 \%$ & 29,197 & $82.9 \%$ & 210 & 840 & $300.6 \%$ & 12,775 & 20,945 FRA & 7,115 & $24.4 \%$ & 24,659 & 3,232 & $13.1 \%$ & 21,212 & $86.0 \%$ & 136 & 850 & $524.7 \%$ & 10,518 & 15,466 MUC & 5,600 & $26.4 \%$ \\
\hline ARN & 41,818 & 3,867 & $9.2 \%$ & 23,159 & $55.4 \%$ & 174 & 742 & & 9,138 & 7 FRA & 4,46 & & 37,390 & 3,484 & $9.3 \%$ & & & 125 & 71 & 467 & 8,365 & $32,334 \mathrm{CPH}$ & 3,834 & $\%$ \\
\hline OSL & 47,340 & 5,854 & $12.4 \%$ & 29,695 & $62.7 \%$ & 133 & 601 & $353.3 \%$ & 9,663 & $34,909 \mathrm{CPH}$ & 3,460 & $7 \%$ & 44,455 & 5,603 & $12.6 \%$ & 28,110 & $63.2 \%$ & 105 & 581 & $455.3 \%$ & 9,295 & $31,421 \mathrm{BGO}$ & 3,212 & $11.4 \%$ \\
\hline
\end{tabular}

Appendix B. Simulation results: Airport closure on Monday, February $4^{\text {th }} 2013$ between from 00:00 to 23:59 UTC; unrestricted passenger recovery.

\begin{tabular}{|c|c|c|c|c|c|c|c|c|c|c|c|c|c|c|c|c|c|c|c|c|c|c|c|c|}
\hline \multirow{2}{*}{$\begin{array}{l}\text { Closed } \\
\text { Airport }\end{array}$} & \multirow{2}{*}{\multicolumn{12}{|c|}{ All markets }} & \multicolumn{12}{|c|}{ intra-EEA markets } \\
\hline & dpax & & & & & & & & & & & \%reloc & dpax & conn & \%conn & reloc & $\%$ reloc & & avt & $\Delta \%$ & aggdel & aggdel' alt. & $\Delta p a x$ & \%reloc \\
\hline LHR & 108,197 & 13,896 & $12.8 \%$ & 90,504 & $83.6 \%$ & 368 & 676 & $83.9 \%$ & 19,390 & $41,214 \mathrm{LGW}$ & 10,124 & $11.2 \%$ & 59,333 & 3,604 & $6.1 \%$ & 48,724 & $82.1 \%$ & 149 & 571 & $84.2 \%$ & 14,290 & $27,572 \mathrm{LGW}$ & 7,319 & $15.0 \%$ \\
\hline CDG & 78,532 & 13,472 & $17.2 \%$ & 66,891 & $85.2 \%$ & & 631 & $90.9 \%$ & 13,952 & 28,731 ORY & 15,966 & $23.9 \%$ & 47,663 & 4,701 & $9.9 \%$ & 40,188 & $84.3 \%$ & 161 & 56 & $51.8 \%$ & 11,339 & 20,707 ORY & 0,900 & \\
\hline FRA & 69,499 & 21,971 & $31.6 \%$ & 66,306 & $95.4 \%$ & 369 & 563 & $52.6 \%$ & 8,937 & 13,011 DUS & 10,208 & $15.4 \%$ & 39,798 & 8,970 & $22.5 \%$ & 38,186 & $95.9 \%$ & 176 & 412 & $133.6 \%$ & 6,244 & 8,241 DUS & 7,072 & $18.5 \%$ \\
\hline IST & 410 & 21,130 & $28.0 \%$ & 62,428 & $82.8 \%$ & 306 & 794 & $159.1 \%$ & 21,125 & 38,365 SAW & 9,634 & $15.4 \%$ & 165 & 165 & $100.0 \%$ & 163 & $98.8 \%$ & 428 & 384 & $-10.2 \%$ & -5 & -1 MUC & 54 & $33.1 \%$ \\
\hline AMS & 63,250 & 12,595 & $19.9 \%$ & 51,214 & $81.0 \%$ & 307 & 711 & $131.4 \%$ & 14,357 & $29,878 \mathrm{BRU}$ & 13,953 & $27.2 \%$ & 45,988 & 5,408 & $11.8 \%$ & 36,111 & $78.5 \%$ & 161 & 673 & $317.8 \%$ & 12,831 & $25,378 \mathrm{BRU}$ & 11,536 & $31.9 \%$ \\
\hline $\mathrm{AD}$ & 386 & 9,419 & $13.8 \%$ & 51,507 & $75.3 \%$ & 247 & 930 & $277.2 \%$ & 24,458 & $46,035 \mathrm{BCN}$ & 9,669 & $18.8 \%$ & 57,085 & 5,148 & $9.0 \%$ & 41,925 & $73.4 \%$ & 152 & 912 & $501.5 \%$ & 22,142 & $41,385 \mathrm{BCN}$ & 8,734 & $20.8 \%$ \\
\hline & 479 & 14,606 & 23 & 59 & 93 & & 63 & $191.4 \%$ & 1 & $3 \mathrm{~S}$ & 7,13 & & 8,422 & 8,7 & $18 .($ & 45,2 & 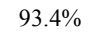 & 136 & & & 95 & $46 s$ & 72 & $2.5 \%$ \\
\hline $\mathrm{FCO}$ & 017 & 8,474 & $15.4 \%$ & 45,856 & $83.3 \%$ & 227 & 891 & $293.2 \%$ & 21,167 & 32,696 LIN & 5,995 & $13.1 \%$ & 42,482 & 4,692 & $11.0 \%$ & 34,967 & $82.3 \%$ & 132 & 894 & $579.5 \%$ & 18,504 & 27,868 LIN & 5,368 & $15.4 \%$ \\
\hline LGW & 929 & 1,611 & $2.7 \%$ & 37,580 & $62.7 \%$ & 174 & 382 & $119.2 \%$ & 5,421 & 37,217 LHR & 15,044 & $40.0 \%$ & 50,351 & 963 & $1.9 \%$ & 32,818 & $65.2 \%$ & 134 & 352 & $162.4 \%$ & 4,959 & 29,531 LHR & 12,996 & $39.6 \%$ \\
\hline $\mathrm{N}$ & 825 & 2,360 & $3.6 \%$ & 31,064 & $47.9 \%$ & 180 & 972 & $438.7 \%$ & 17,070 & 61,965 MAD & 9,077 & $29.2 \%$ & 58,220 & 1,957 & $3.4 \%$ & 27,143 & $46.6 \%$ & 134 & 976 & $628.7 \%$ & 15,865 & 57,078 MAD & 8,072 & $29.7 \%$ \\
\hline & & 4,658 & $10.0 \%$ & & & & & 17 & & $9 \mathrm{SVO}$ & 10,660 & & 0 & 0 & & 0 & & & & & & 0 & 0 & $0.0 \%$ \\
\hline ORY & 448 & 2,013 & $3.6 \%$ & 40,230 & $72.6 \%$ & 13 & 415 & $199.2 \%$ & 7,715 & $28,113 \mathrm{CDG}$ & 17,511 & 43.5 & 44,972 & 1,770 & $3.9 \%$ & 33,185 & $73.8 \%$ & 124 & 401 & $222.4 \%$ & 6,376 & $21,906 \mathrm{CDG}$ & 14,040 & $42.3 \%$ \\
\hline $\mathrm{CPH}$ & & 6,672 & $15.3 \%$ & 3 & $73.5 \%$ & & 842 & $293.8 \%$ & 13,9 & 1 FRA & 5,209 & & 37,531 & 5,477 & $14.6 \%$ & 27,566 & & 147 & & $471.2 \%$ & 13,258 & 25,837 FRA & 4,919 & $17.8 \%$ \\
\hline & & 6,287 & 18.3 & & & & & & & $2 \mathrm{~S}$ & 5,386 & & & 3,1 & 12. & & & 15 & & $249.9 \%$ & 5,714 & 9,133 STR & 4,311 & $19.7 \%$ \\
\hline GVA & & 393 & 1.1 & & & & & & & $6 \mathrm{LY}$ & & & 28,670 & 25 & 0.9 & & $68.6 \%$ & 117 & & $731.9 \%$ & 11,680 & $23,364 \mathrm{~L}$ & 6,753 & $34.3 \%$ \\
\hline MX & & 463 & 1. & 805 & 67 & & 47 & 14 & 12 & 5 LIN & 8,0 & & 32 & 209 & 0. & 04 & $68.0 \%$ & 119 & & $6 \%$ & 4,261 & $48 \mathrm{~L}$ & 6,609 & $34.8 \%$ \\
\hline ST & & 47 & & & & & & & & $4 \mathrm{LF}$ & & & & 43 & & & & 118 & & & 5,111 & 32 LHR & 7,849 & $35.8 \%$ \\
\hline DUB & & 1,051 & 3. & 24 & 71 & 16 & 94 & $\%$ & 13,392 & $0 \mathrm{~L}$ & 5,720 & 23. & 56 & 789 & $2.5 \%$ & 22 , & $72.4 \%$ & 127 & 965 & $660.0 \%$ & 13,344 & 24,873 LHR & 5,852 & $25.5 \%$ \\
\hline DL & & 2,746 & & 32 & & & 36 & & & & 7,9 & & 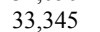 & 2,00 & 6.0 & & & 12 & & & 3,803 & 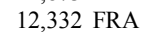 & 35 & $23.6 \%$ \\
\hline MI & & 701 & 2. & 22 & 71 & 22 & 71 & & & & 5,2 & & 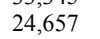 & 48 & & & & 14 & & & 6,942 & $\mathrm{x}$ & 48 & $23.8 \%$ \\
\hline & & 2, & & & & & & & & 11 & & & & 1,8 & & & & & & & $\begin{array}{l}0,053 \\
4,042\end{array}$ & US & $\begin{array}{l}4,387 \\
4,387\end{array}$ & $19.6 \%$ \\
\hline VIE & 217 & 7,509 & $21.3 \%$ & 33 & 93 & 22 & 838 & 28 & 14,2 & 16 & 7,121 & 21. & 24 & 3,232 & $13.1 \%$ & 22 & $93.0 \%$ & 139 & 868 & 52 & 11,607 & 13,799 FRA & 5,736 & $25.0 \%$ \\
\hline $\mathrm{AR}$ & & 3,867 & & 010 & 65 & 17 & 78 & 0 & & $875 \mathrm{CPH}$ & 4,3 & & & 3 , & & & $69.3 \%$ & 30 & 78 & & 197 & $76 \mathrm{CPH}$ & 940 & $5.2 \%$ \\
\hline OSL & 47,340 & 5,854 & $12.4 \%$ & 5,386 & $.7 \%$ & 143 & 707 & $393.6 \%$ & 13,852 & $9,019 \mathrm{CPH}$ & 5,143 & $14.5 \%$ & 44.455 & 5,603 & $12.6 \%$ & 33,421 & $75.2 \%$ & 118 & 694 & $490.2 \%$ & 13,379 & 27,238 BGO & 4,904 & $4.7 \%$ \\
\hline
\end{tabular}

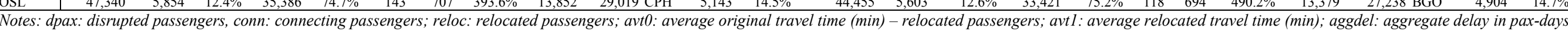
-relocated passengers; aggdel': aggregate delay in pax-days for all passengers at 23:59 on Tuesday, Feb $5^{\text {th }}$ 2013; alt: main alternate airport; $\Delta$ pax: number of relocated passenger departures at the alternate airport. 
Appendix C. Simulation results: Airport closure on Monday, February $4^{\text {th }} 2013$ between from 00:00 to 23:59 UTC; passenger recovery via alliance network; unlimited capacity.

\begin{tabular}{|c|c|c|c|c|c|c|c|c|c|c|c|c|c|c|c|c|c|c|c|c|c|c|c|c|}
\hline \multirow{2}{*}{$\begin{array}{l}\text { Closed } \\
\text { Airport }\end{array}$} & \multicolumn{12}{|c|}{ All markets } & \multicolumn{12}{|c|}{ intra-EEA markets } \\
\hline & dpax & conn & $\%$ conn & reloc & \%reloc & avto & avt1 & $\Delta a v t \%$ & aggdel & aggdel' alt. & $\Delta p a x$ & \%reloc & dpax & conn & $\%$ conn & reloc & \%reloc & & avt & $\Delta \%$ & aggdel & aggdel' alt. & $\Delta p a x$ & \%reloc \\
\hline$\overline{\mathrm{LHR}}$ & 108,197 & 13,896 & $12.8 \%$ & 104,390 & $96.5 \%$ & 344 & 566 & $64.4 \%$ & 16,073 & 20,997 LGW & 10,013 & $9.6 \%$ & 59,333 & 3,604 & $6.1 \%$ & 58,693 & $98.9 \%$ & 143 & 346 & $143 \%$ & 8,302 & $9,138 \mathrm{LGW}$ & 7,815 & $13.3 \%$ \\
\hline CDG & 78,532 & 13,472 & $17.2 \%$ & 73,342 & $93.4 \%$ & 308 & 551 & $78.9 \%$ & 12,373 & 19,764 ORY & 17,302 & $23.6 \%$ & 47,663 & 4,701 & $9.9 \%$ & 46,285 & $97.1 \%$ & 153 & 379 & $148 \%$ & 7,270 & 9,092 ORY & 13,844 & $29.9 \%$ \\
\hline IST & 75,410 & 21,130 & $28.0 \%$ & 70,555 & $93.6 \%$ & 287 & 533 & $85.6 \%$ & 12,036 & 18,798 FRA & 18,048 & $25.6 \%$ & 165 & 165 & $100.0 \%$ & 155 & $93.9 \%$ & 423 & 407 & $-4 \%$ & 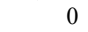 & $16 \mathrm{MUC}$ & 59 & $8.1 \%$ \\
\hline FRA & 69,499 & 21,971 & $31.6 \%$ & 65,357 & $94.0 \%$ & 361 & 575 & $59.4 \%$ & 9,735 & 15,728 DUS & 11,331 & $17.3 \%$ & 39,798 & 8,970 & $22.5 \%$ & 38,638 & $97.1 \%$ & 171 & 369 & $116 \%$ & 5,318 & 6,944 DUS & 8,154 & $21.1 \%$ \\
\hline MAD & 68,386 & 9,419 & $13.8 \%$ & 64,186 & $93.9 \%$ & 225 & 622 & $176.0 \%$ & 17,670 & $23,580 \mathrm{BCN}$ & 8,923 & $13.9 \%$ & 57,085 & 5,148 & $9.0 \%$ & 54,454 & $95.4 \%$ & 144 & 542 & $275 \%$ & 15,032 & $18,651 \mathrm{BCN}$ & 7,382 & $13.6 \%$ \\
\hline IUC & 63,479 & 14,606 & $23.0 \%$ & 60,486 & $95.3 \%$ & 213 & 456 & $114.1 \%$ & 10,199 & 14,064 FRA & 9361 & $15.5 \%$ & 48,422 & 8,721 & $18.0 \%$ & 46,504 & $96.0 \%$ & 130 & 38 & $193 \%$ & . & $2,466 \mathrm{STR}$ & 8019 & $17.2 \%$ \\
\hline AMS & 63,250 & 12,595 & $19.9 \%$ & 59,361 & $93.9 \%$ & 269 & 562 & $108.7 \%$ & 12,068 & $17,754 \mathrm{BRU}$ & 12,081 & $20.4 \%$ & 45,988 & 5,408 & $11.8 \%$ & 44,430 & $96.6 \%$ & 145 & 454 & $213 \%$ & 9,521 & 11,693 BRU & 10,129 & $22.8 \%$ \\
\hline LGW & 59,929 & 1,611 & $2.7 \%$ & 49,401 & $82.4 \%$ & 160 & 333 & $108.4 \%$ & 5,933 & 21,396 LHR & 5,124 & $10.4 \%$ & 50,351 & 963 & $1.9 \%$ & 44,315 & $88.0 \%$ & 124 & 300 & $143 \%$ & 5,438 & 13,978 LTN & 4,891 & $11.0 \%$ \\
\hline ORY & 55,448 & 2,013 & $3.6 \%$ & 51,275 & $92.5 \%$ & 145 & 319 & $119.3 \%$ & 6,170 & $12,212 \mathrm{CDG}$ & 13,819 & $27.0 \%$ & 44,972 & 1,770 & $3.9 \%$ & 44,238 & $98.4 \%$ & 129 & 292 & $125 \%$ & 4,987 & $5,983 \mathrm{CDG}$ & 13,143 & $29.7 \%$ \\
\hline$\Omega$ & 55,017 & 8,474 & $15.4 \%$ & 51,040 & $92.8 \%$ & 214 & 606 & $182.8 \%$ & 13,889 & $19,515 \mathrm{CDG}$ & 10,763 & $21.1 \%$ & 42,482 & 4,692 & $11.0 \%$ & 40,442 & $95.2 \%$ & 125 & 54 & $331 \%$ & 11,641 & $14,392 \mathrm{CDG}$ & 7,481 & $18.5 \%$ \\
\hline & 47,340 & 5,854 & $12.4 \%$ & 42,906 & $90.6 \%$ & 136 & 463 & $239.7 \%$ & 9,730 & $15,964 \mathrm{SVG}$ & 6,962 & $16.2 \%$ & 44,455 & 5,603 & $12.6 \%$ & 40,640 & $91.4 \%$ & 108 & 440 & $307 \%$ & 9,359 & $14,793 \mathrm{SVG}$ & 6,685 & $16.4 \%$ \\
\hline $\mathrm{CPH}$ & 43,467 & 6,672 & $15.3 \%$ & 40,545 & $93.3 \%$ & 195 & 463 & $137.8 \%$ & 7,555 & 11,582 ARN & 7,675 & $18.9 \%$ & 37,531 & 5,477 & $14.6 \%$ & 35,379 & $94.3 \%$ & 130 & 411 & $216 \%$ & 6,911 & 9,774 ARN & 6,834 & $19.3 \%$ \\
\hline ARN & 41,818 & 3,867 & $9.2 \%$ & 39,287 & $93.9 \%$ & 166 & 397 & $138.8 \%$ & 6,302 & $9,646 \mathrm{CPH}$ & 6,849 & $17.4 \%$ & 37,390 & 3,484 & $9.3 \%$ & 35,399 & $94.7 \%$ & 119 & 34 & $191 \%$ & 5,597 & $8,536 \mathrm{CPH}$ & 6,065 & $17.1 \%$ \\
\hline & & 2,746 & $6.7 \%$ & 38,401 & 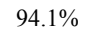 & 169 & 355 & 110 & 4,9 & 8,271 FRA & 8,127 & 21.2 & 33,345 & 2,001 & $6.0 \%$ & 31,926 & $95.7 \%$ & 114 & 30 & $169 \%$ & 4,264 & $6,220 \mathrm{~F}$ & 6,580 & $20.6 \%$ \\
\hline SVO & 40,299 & 8,422 & $20.9 \%$ & 37,883 & 94 & 336 & 588 & $75.0 \%$ & 6,6 & 10,220 AMS & 6,528 & $17.2 \%$ & 38 & 38 & $100.0 \%$ & 29 & $76.3 \%$ & 461 & 90 & $96 \%$ & 9 & $25 \mathrm{CDG}$ & 12 & $41.4 \%$ \\
\hline MXP & 36,894 & 463 & $1.3 \%$ & 34,129 & 92 & 185 & 412 & $122.7 \%$ & 5,3 & 9,248 LIN & 4,596 & $13.5 \%$ & 27,932 & 209 & $0.7 \%$ & 26,730 & $95.7 \%$ & 117 & 36 & $214 \%$ & 4,640 & 6,312 LGW & 4,107 & $15.4 \%$ \\
\hline STN & 35,871 & 47 & & 33,452 & $93.3 \%$ & 120 & 338 & $182.1 \%$ & 5,073 & 8,478 DUB & 3,260 & 9.7 & 35,357 & 43 & $0.1 \%$ & 32,971 & $93.3 \%$ & 116 & 33 & $187 \%$ & 4,989 & 8,426 DUB & 3,260 & $9.9 \%$ \\
\hline VIE & 35,217 & 7,509 & $21.3 \%$ & 33,457 & 95 & 214 & 497 & $131.8 \%$ & 6 , & $8,936 \mathrm{GRZ}$ & 7,358 & $22.0 \%$ & 24,659 & 3,232 & $13.1 \%$ & 23,821 & $96.6 \%$ & 135 & 42 & $213 \%$ & 4,744 & $5,884 \mathrm{GRZ}$ & 6,424 & $27.0 \%$ \\
\hline 11 & 34,432 & 6,287 & $18.3 \%$ & 33 & 94 & 261 & 4 & 71. & 4,227 & $6,973 \mathrm{STR}$ & 6,481 & 200 & 24,579 & 3,181 & $12.9 \%$ & 23,438 & $95.4 \%$ & 14 & & $140 \%$ & 3,244 & $4,740 \mathrm{STR}$ & 4,850 & $20.7 \%$ \\
\hline DUB & 34 & 1,051 & & & & 148 & 420 & 183 & 5, & $10,505 \mathrm{BHX}$ & 3,2 & 10 & & 78 & 2.5 & 29,303 & $92.6 \%$ & 11 & 39 & $243 \%$ & 5,728 & $8,922 \mathrm{BHX}$ & 3,224 & $11.0 \%$ \\
\hline GVA & 3 & 393 & 0 & 32 & 94 & 165 & 417 & 152 & 5 , & 8,349 LYS & 10,4 & 32. & 28,670 & 256 & $0.9 \%$ & 27,204 & $94.9 \%$ & 114 & 37 & $228 \%$ & 4,890 & 6,825 LYS & 8,974 & $33.0 \%$ \\
\hline BRU & 33, & 2,573 & $7.7 \%$ & 31,230 & $93.1 \%$ & 202 & 422 & $108.8 \%$ & 4,775 & 7,728 DUS & 6,473 & 20.7 & 25,995 & 1,800 & $6.9 \%$ & 25,537 & $98.2 \%$ & 137 & 368 & $169 \%$ & 4,104 & 4,731 DUS & 5,454 & $21.4 \%$ \\
\hline MAN & 31,747 & 701 & $2.2 \%$ & 24,493 & $77.2 \%$ & 209 & 415 & $98.7 \%$ & 3,506 & 13,867 BHX & 5,230 & $21.4 \%$ & 24,657 & 481 & $2.0 \%$ & 20,854 & $84.6 \%$ & 136 & 355 & $161 \%$ & 3,172 & 8,379 BHX & 4,615 & 22.1 \\
\hline
\end{tabular}

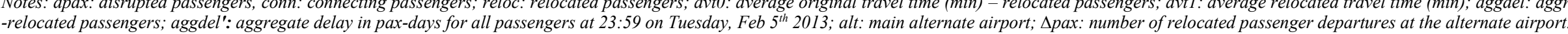

Appendix D. Simulation results: Airport closure on Friday, February $8^{\text {th }} 2013$ between from 00:00 to 23:59 UTC; passenger recovery via airline network.

\begin{tabular}{|c|c|c|c|c|c|c|c|c|c|c|c|c|c|c|c|c|c|c|c|c|c|c|c|c|}
\hline \multirow{2}{*}{ 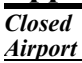 } & \multicolumn{12}{|c|}{ All markets } & \multicolumn{12}{|c|}{ intra-EEA markets } \\
\hline & $d p a x$ & conn & \%conn & reloc & \%reloc & avt 0 & avt1 & $\Delta a v t \%$ & aggdel & aggdel' alt. & $\Delta p a x$ & \%reloc & $d p a x$ & conn & \%conn & reloc & \%reloc & avto & avt1 & $\Delta \%$ & aggdel & aggdel' alt. & $\Delta p a x$ & \%reloc \\
\hline LHR & 127,326 & 16,206 & $12.7 \%$ & 94,258 & $74.0 \%$ & 423 & 951 & $125.0 \%$ & 34,586 & $78,702 \mathrm{MAD}$ & 6,097 & $6.4 \%$ & 61,934 & 3,015 & $4.9 \%$ & 43,429 & $70.1 \%$ & 187 & 837 & $47.4 \%$ & 19,592 & 43,392 FRA & 4,875 & $11.2 \%$ \\
\hline $\mathrm{CDG}$ & 95,364 & 14,287 & $15.0 \%$ & 66,798 & $70.0 \%$ & 416 & 817 & $96.2 \%$ & 18,573 & 58,962 ORY & 10,763 & $16.1 \%$ & 52,129 & 3,594 & $6.9 \%$ & 35,443 & $68.0 \%$ & 221 & 685 & $209.4 \%$ & 11,414 & 48 & & \\
\hline FRA & 78,412 & 21,040 & $26.8 \%$ & 66,813 & $85.2 \%$ & 420 & 691 & $64.8 \%$ & 12,607 & 29,155 DUS & 11,429 & $17.1 \%$ & 42,217 & 7,928 & $18.8 \%$ & 36,516 & $86.5 \%$ & 222 & 507 & $128.7 \%$ & 7,234 & 14,966 DUS & 7,127 & $19.5 \%$ \\
\hline IST & 76,768 & 18,925 & $24.7 \%$ & 53,038 & $69.1 \%$ & 312 & 789 & $152.9 \%$ & 17,578 & 50,970 FRA & 10,495 & $19.8 \%$ & 120 & 120 & $100.0 \%$ & 115 & $95.8 \%$ & 413 & 397 & $-3.9 \%$ & -1 & $7 \mathrm{MUC}$ & 55 & $47.8 \%$ \\
\hline AMS & 70,289 & 12,583 & $17.9 \%$ & 43,454 & $61.8 \%$ & 393 & 832 & $111.6 \%$ & 13,244 & $51,336 \mathrm{CDG}$ & 11,203 & $25.8 \%$ & 48,116 & 4,516 & $9.4 \%$ & 27,192 & $56.5 \%$ & 202 & 736 & $263.7 \%$ & 10,071 & $39,038 \mathrm{CDG}$ & 6,879 & $25.3 \%$ \\
\hline MUC & 65,926 & 13,205 & $20.0 \%$ & 53,014 & $80.4 \%$ & 244 & 731 & $199.7 \%$ & 17,938 & 35,106 FRA & 11,093 & $20.9 \%$ & 9,991 & 7,795 & $15.6 \%$ & 39,425 & $78.9 \%$ & 151 & 707 & $.9 \%$ & 5,214 & 137 FRA & 8,781 & $22.3 \%$ \\
\hline FCO & 58,250 & 7,410 & $12.7 \%$ & 33,968 & $58.3 \%$ & 279 & 960 & $244.3 \%$ & 16,065 & $49,648 \mathrm{CDG}$ & 7,546 & $22.2 \%$ & 44,553 & 4,087 & $9.2 \%$ & 24,157 & $54.2 \%$ & 159 & 949 & $498.0 \%$ & 13,260 & $41,067 \mathrm{CDG}$ & 5,120 & $21.2 \%$ \\
\hline LGW & 67,330 & 1,405 & $2.1 \%$ & 27,127 & $40.3 \%$ & 198 & 413 & $108.9 \%$ & 4,056 & 61,508 LHR & 5,466 & $20.1 \%$ & 55,198 & 835 & $1.5 \%$ & 22,234 & $40.3 \%$ & 124 & 346 & $179.1 \%$ & 3,430 & 49,439 LHR & 3,780 & $17.0 \%$ \\
\hline $\mathrm{BCN}$ & 68,834 & 2,145 & $3.1 \%$ & 23,603 & $34.3 \%$ & 222 & 900 & $306.0 \%$ & 11,117 & $73,506 \mathrm{MAD}$ & 5,476 & $23.2 \%$ & 62,033 & 1,885 & $3.0 \%$ & 19,876 & $32.0 \%$ & 151 & 878 & $480.9 \%$ & 10,031 & 67,862 MAD & 5,067 & $25.5 \%$ \\
\hline $\mathrm{NIL}$ & 709 & 4,291 & $8.1 \%$ & 21,034 & $39.9 \%$ & 280 & 532 & $89.8 \%$ & 3,675 & $51,747 \mathrm{SVO}$ & 1,390 & $6.6 \%$ & 政 & 0 & & 0 & & & & & & 0 & 0 & $0.0 \%$ \\
\hline SVO & 43,188 & 7,811 & $18.1 \%$ & 28,176 & $65.2 \%$ & 346 & 835 & $141.1 \%$ & 9,556 & $31,160 \mathrm{CDG}$ & 6,168 & $21.9 \%$ & 32 & 32 & $100.0 \%$ & 13 & $40.6 \%$ & 538 & 684 & $27.1 \%$ & 1 & $35 \mathrm{CDG}$ & 6 & $46.2 \%$ \\
\hline $\mathrm{CPH}$ & 44,940 & 6,047 & $13.5 \%$ & 20,152 & $44.8 \%$ & 275 & 867 & $215.3 \%$ & 8,283 & 42,752 FRA & 4,689 & $23.3 \%$ & 38,182 & 4,936 & $12.9 \%$ & 15,797 & $41.4 \%$ & 173 & 842 & $388.2 \%$ & 7,348 & 38,238 FRA & 4,159 & $26.3 \%$ \\
\hline $\mathrm{RH}$ & 37,770 & 6,128 & $16.2 \%$ & 30,089 & 9.1 & 297 & 723 & $143.3 \%$ & & 91 STR & 6,377 & 21.2 & 25,948 & 2,815 & $10.8 \%$ & 19,918 & $76.8 \%$ & 154 & 711 & $360.4 \%$ & 7,696 & 15,746 STR & 4,645 & $23.3 \%$ \\
\hline GVA & 38,192 & 303 & $0.8 \%$ & 19,833 & $1.9 \%$ & 208 & 813 & $290.0 \%$ & 8,327 & 32,796 LYS & 4,600 & 23. & 31,928 & 171 & $0.5 \%$ & 15,365 & $48.1 \%$ & 135 & 829 & $516.2 \%$ & 7,413 & 29,739 LYS & 3,022 & $19.7 \%$ \\
\hline MXP & 40,622 & 530 & $1.3 \%$ & 16,973 & $41.8 \%$ & 276 & 632 & $129.2 \%$ & 4,200 & 36,915 LIN & 2,816 & $16.6 \%$ & 29,959 & 153 & $0.5 \%$ & 10,636 & $35.5 \%$ & 148 & 668 & $352.3 \%$ & 3,845 & 30,627 LIN & 1,652 & $15.5 \%$ \\
\hline STN & & 56 & $0.1 \%$ & 16,835 & 44. & 123 & 583 & 374. & & 35,725 BRS & 1,868 & 11. & 37,299 & 51 & 0.1 & 16,548 & 44 & 119 & 576 & $385.5 \%$ & 5,258 & 34,756 BRS & 1,868 & $11.3 \%$ \\
\hline UB & 38,814 & 976 & $2.5 \%$ & 16,175 & $41.7 \%$ & 197 & 553 & $179.9 \%$ & 3,990 & 36,530 LHR & $\begin{array}{l}1,335 \\
\end{array}$ & $8.3 \%$ & 35,343 & 658 & $1.9 \%$ & 14,122 & $40.0 \%$ & 135 & 523 & $288.2 \%$ & 3,811 & $31,901 \mathrm{STN}$ & $\begin{array}{l}1,265 \\
-1\end{array}$ & $9.0 \%$ \\
\hline DUS & 42,594 & 2,132 & $5.0 \%$ & 27,148 & $63.7 \%$ & 194 & 507 & $161.8 \%$ & 5,903 & 44 FRA & 8,828 & 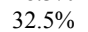 & 85 & 1,480 & $4.4 \%$ & 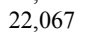 & $64.9 \%$ & 13 & 481 & & 5,365 & 22,174 FRA & 7,326 & $33.2 \%$ \\
\hline MAN & 35,096 & 585 & $1.7 \%$ & 17,928 & $1.1 \%$ & 250 & 671 & $168.7 \%$ & 5,247 & $35 \mathrm{BHX}$ & 3,7 & 21.2 & 94 & 443 & 1.6 & 14,277 & $52.1 \%$ & 15 & 648 & $328.3 \%$ & 4, & $4 \mathrm{BH}$ & 3,040 & $21.3 \%$ \\
\hline RU & 3. & 2,039 & 5. & 22,262 & & 242 & 575 & 137 & 5,142 & 21,218 DUS & 6,434 & 28. & 28 & 1,336 & $5.0 \%$ & 17,443 & $65.5 \%$ & 168 & 518 & $208.7 \%$ & 4,239 & 17,147 DUS & 5,248 & $30.1 \%$ \\
\hline VIE & 36,249 & 6,637 & $18.3 \%$ & 26,376 & 72.8 & 250 & 913 & $266.0 \%$ & 12,155 & 25,489 FRA & 6,920 & $26.2 \%$ & 24,943 & 2,731 & $10.9 \%$ & 17,440 & $69.9 \%$ & 166 & 958 & $476.2 \%$ & 9,588 & 19,793 FRA & 5,039 & $28.9 \%$ \\
\hline ARN & 41, & 3,247 & $7.8 \%$ & 12,022 & 28 & 240 & 937 & $291.2 \%$ & 5,823 & 45,175 FRA & 2,764 & 23. & 37,636 & 3,028 & $8.0 \%$ & $\begin{array}{l}10,063 \\
\end{array}$ & $26.7 \%$ & 164 & 928 & $465.6 \%$ & 5,336 & 46,112 FRA & 2,579 & $25.6 \%$ \\
\hline $\mathrm{SL}$ & 48,274 & 5,465 & $11.3 \%$ & 15,015 & $1.1 \%$ & 187 & 875 & $367.7 \%$ & 7,172 & 53,921 FRA & 2,948 & $19.6 \%$ & 45,277 & 5,250 & $11.6 \%$ & 13,463 & $29.7 \%$ & 133 & 851 & $538.7 \%$ & 6,710 & 53,464 FRA & 2,798 & $20.8 \%$ \\
\hline
\end{tabular}

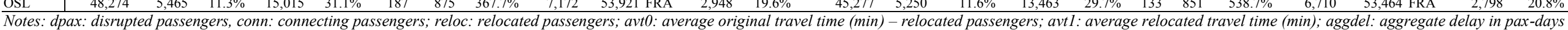
-relocated passengers; aggdel': aggregate delay in pax-days for all passengers at 23:59 on Saturday, Feb $9^{\text {th }}$ 2013; alt: main alternate airport; $\Delta$ pax: number of relocated passenger departures at the alternate airport. 
Appendix E. Simulation results: Airport closure on Monday, August $5^{\text {th }} 2013$ between from 00:00 to 23:59 UTC; passenger recovery via airline network.

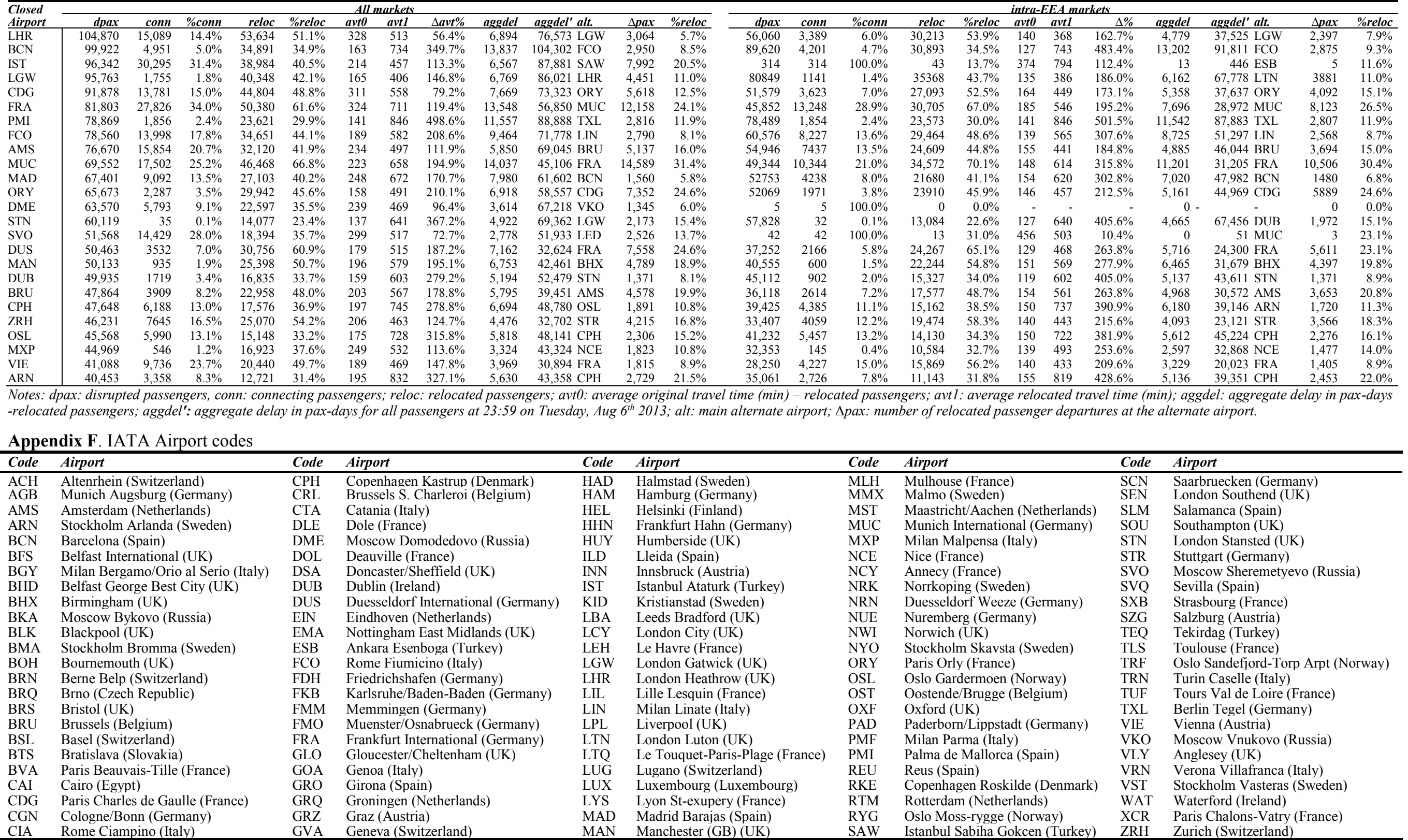


2017-01-05

\section{Vulnerability of the European air}

transport network to major airport

closures from the perspective of

passenger delays: Ranking the most

critical airports

\section{Voltes-Dorta, Augusto}

Elsevier

Voltes-Dorta A, Rodríguez-Déniz H, Suau-Sanchez P, Vulnerability of the European air transport network to major airport closures from the perspective of passenger delays: Ranking the most critical airports, Transportation Research Part A: Policy and Practice, Volume 96, pÿFebruary 2017, Pages 119145

http://dx.doi.org/10.1016/j.tra.2016.12.009

Downloaded from Cranfield Library Services E-Repository 